\title{
(A) The genesis of mud volcano conduits through thick
}

\section{evaporite sequences}

\author{
C. Kirkham *, J. Cartwright *, C. Hermanrud †, C. Jebsen $¥$ \\ * Department of Earth Sciences, University of Oxford, South Parks Road, Oxford, UK \\ † Statoil ASA, N-7005 Trondheim, Norway \\ ¥ Statoil, N4032 Stavanger, Norway
}

\section{(B) ABSTRACT}

This paper documents the seismic expression of the conduits underlying over 350 mud volcanoes that were erupted in an area of the western Nile Cone in the past 5.3 Myrs. The study is based on a c. 4300 $\mathrm{km}^{2}$ 3D seismic survey. The conduits are interpreted to transect the $>1000 \mathrm{~m}$ thick Messinian Evaporite succession, demonstrating that the eruptive process is sufficiently dynamic to breach the formidable seal represented by the evaporites. The mud volcano conduits are remarkably similar in geometry and seismic characteristics to many previously described examples of fluid escape pipes. They are vertical to sub-vertical structures with a crudely cylindrical geometry, but that can either widen or narrow upwards towards their upper terminations in the mud volcano edifices. Imaging at depth within the Messinian Evaporites and pre-evaporite successions is more uncertain, but direct sampling of mud from surface volcanoes suggests a pre-Messinian source, confirming the seismic interpretation that they root within pre-salt stratigraphy. A conceptual model for the genesis of these mud volcano conduits through salt is proposed, for which hydraulic fracturing is driven by high overpressures that developed in the pre-salt source stratigraphy as a response to the Messinian Salinity Crisis. Dissolution and removal of evaporites resulting in fracturing and collapse via a stoping mechanism which is a slow process by comparison to hydraulic fracturing but is argued to potentially 
contribute to conduit formation. The analysis presented here demonstrates the potential for bypassing a $>1 \mathrm{~km}$ thick unit of sealing evaporites via focused fluid and sediment mobilisation from deeper overpressured cells in other salt basins worldwide, and has significant implications for hydrocarbon exploration, $\mathrm{CO}_{2}$ sequestration and nuclear waste disposal.

\section{(B) INTRODUCTION}

Mud volcano conduits (MVCs) represent a form of seal bypass system that connects a source stratigraphic unit with an extrusive and constructional mud volcano (Stewart and Davies, 2006; Cartwright et al., 2007; Roberts et al., 2010). In comparison to the better studied surface edifice of mud volcanoes, MVCs have received only limited attention in the general research conducted to date on mud volcano geometry and internal structure. This dominance of effort on the edifice in part reflects their more easily observable surface expression and clearer imaging on seismic profiles (Fowler et al., 2000; Graue, 2000; Evans et al., 2007; Huguen et al., 2009; Mascle et al., 2014; Kirkham et al., 2017).

Several different models for MVCs have previously been proposed including large diapirs (Brown, 1990), steep mud injections or diatremes (Pickering et al., 1988; Robertson and Kopf, 1998; Clari et al., 2004), or narrow and vertical pipe-like structures (Fig. 1) (Fowler et al., 2000; Graue, 2000; Kopf, 2002; Stewart and Davies, 2006; Roberts et al., 2010; Reiche et al., 2014).

Recent advances in seismic imaging and increasing availability of 3D seismic data in areas where mud volcanism occurs has increasingly led to the recognition that MVCs are pipe-like in gross geometry (Fig. 1). They have been observed to be tens of meters in diameter and extend vertically for hundreds of meters from a source interval to an extruded edifice (Fig. 1) (Fowler et al., 2000; Graue, 2000; Davies and Stewart, 2005; Stewart and Davies, 2006; Calves et al., 2010). Through 3D seismic observations of a giant mud volcano in the South Caspian Basin, Davies and Stewart (2005) proposed 
that a typical MVC consists of a pipe structure that is represented either by a cylindrical zone of heavily intruded country rock or by an amalgamation of mud pipes. Nevertheless, there remains a great deal of uncertainty regarding the detailed internal structure of MVCs (Davies and Stewart, 2005; Stewart and Davies, 2006).

In this paper, we present the results of an interpretation of a high resolution 3D seismic survey located in the lower slope region of the western Nile Cone, offshore Egypt (Fig. 2). This survey is remarkable in that it covers an area of prolific mud volcanism in the Pliocene to Recent that is of a scale comparable to some of the largest mud volcano provinces on Earth (Fig. 2B) (Kirkham et al., 2017). The abundant mud volcanism thus affords an opportunity to compare and contrast the seismic expression of their conduits within a single, well defined geological province, with only limited lateral variability in the stratigraphy of the intervals transected by the MVCs. Numerous fluid escape pipes also within this region present another form of fluid flow phenomena that is vertically focused and can be compared and contrasted to the MVCs (Fig. 2B) (Bertoni and Cartwright, 2015; Cartwright and Santamarina, 2015).

Previous studies of the mud volcanoes exposed at the modern seabed in this region of the Eastern Mediterranean have suggested that the muddy source materials were remobilised from sedimentary units underlying the thick Messinian evaporites (Giresse et al., 2010; Dupré et al., 2014; Mascle et al., 2014; Kirkham et al., 2017). If correct, this implies that the conduits must transect an evaporite succession that is greater than $1000 \mathrm{~m}$ thick, raising important questions as to the sealing properties of evaporites more generally. Evaporites are universally considered to be barriers to fluid migration in sedimentary basins (Downey, 1984), so the recognition of a breaching mechanism or seal bypass for this type of sealing sequence could have significant implications for fluid flow in salt basins more generally (c.f. Cartwright et al. 2007; Warren, 2016).

The main aim of this paper is to document the geometry of the MVCs and from this provide further insights on the genesis of these conduits and the source interval from which the extruded 
material was remobilised. A particular focus of this study, therefore, is the challenging question of seismic evidence relating to the root zones of the MVCs. Secondary aims are to add to our knowledge of mud volcanism by extending the description of MVCs beyond that which has been reported in the limited number of studies published to date.

\section{(B) GEOLOGICAL SETTING}

The study area is located on the lower continental slope offshore Egypt, within the western Nile Deep Sea Fan (NDSF), at approximately $3 \mathrm{~km}$ water depth (Fig. 2). It lies within a passive margin formed following a prolonged period of rifting during the Triassic to Early Cretaceous (Dolson et al., 2005). Late Cretaceous convergence of the African and Eurasian plates resulted in the eventual closure of the Tethys Ocean and continued compressional deformation until the Early Cenozoic (Barber, 1981).

Opening of the Gulf of Suez and tilting of northern Egypt during the upper Eocene to late Oligocene led to large volumes of terrigenous clastics entering the basin, resulting in propagation of the proto Nile Delta and deposition of Upper Eocene to Upper Miocene sedimentary sequences that are predominantly comprised of clay, silt, claystone and marl (Barber, 1981; Bertoni and Cartwright, 2005). Progressive restriction and isolation of the Mediterranean Basin during the late Miocene led to a major drawdown of sea level and the onset of the Messinian Salinity Crisis (MSC). This resulted in widespread erosion of the basin margins and deposition of a succession of evaporites (Fig. 3) up to 3 km thick in deeper basinal regions (Hsü et al., 1977; CIESM, 2008). A restoration to normal marine conditions across the Mediterranean in the early Pliocene brought an end to evaporite deposition and the MSC throughout the Mediterranean (Hsü et al., 1977).

During the Pliocene to Recent, this region has been characterised by the progradation of the NDSF, governed by an abundant supply of terrigenous sediment (clay dominated) from the Nile Delta which is largely sourced from the Red Sea Hills in Egypt, south of the delta where erosion is thought 
to be of the order of $1200-1500$ m (Fig. 2A) (Sestini, 1989; Loncke et al., 2004; Macgregor, 2012). Structurally, the Pliocene to Recent sequence is deformed by thin-skinned tectonics associated with gravitational gliding of the succession overlying a mobile unit of Messinian Evaporites (Fig. 3) (Loncke et al., 2004; Cartwright and Jackson, 2008). The modern western NDSF is characterised by an abundance of fluid escape features including mud volcanoes, fluid escape pipes and pockmarks visible at both the present day seafloor and at buried surfaces throughout the Post-Messinian (Fig. 2B and Fig. 4) (Loncke et al., 2004; Dupré et al., 2014; Mascle et al., 2014).

\section{(C) SEISMIC STRATIGRAPHY WITHIN THE WESTERN NDSF}

In the absence of direct well calibration the interpretation of the stratigraphic units within this study area is based on description of their seismic expression and the identification of certain key regionally correlatable horizons within the Eastern Mediterranean (Fig. 3). The succession is divided into three main seismic-stratigraphic units referred to here as the Pre-Salt Unit, the Messinian Evaporites and the Post-Salt Unit (Fig. 3). The main source rock intervals within the NDSF are found in Upper Cretaceous black shales with high total organic carbon (TOC), Oligocene to Miocene sedimentary rocks and Pliocene sapropels with exceptionally high TOC (Aal et al., 2000; Vandré et al., 2007; Dolson et al., 2005). The principle reservoirs include Pliocene-Pleistocene deepwater channels and basin floor turbidite sands, and Miocene fluvial and turbidite sands (Aal et al., 2000; Dupré et al., 2014).

(D) Pre-Salt Unit

The Pre-Salt Unit comprises seismic facies that are typically of variable amplitude, low frequency but high lateral continuity (Fig. 3). Numerous seismic artefacts (amplitude attenuation and scattering, migration smiles and distortion due to overlying velocity anomalies) within this succession result in 


\section{Kirkham, J. Cartwright, C. Hermanrud, C. Jebsen}

much poorer quality imaging, especially compared to the Post-Salt Unit, as is often the case with increased depth and when imaging beneath salt (O'Brien and Gray, 1996; Muerdter and Ratcliff, 2001). The upper bounding reflection of the Pre-Salt Unit represents a regional unconformity and dips in a northerly direction (Fig. 3). Numerous large basement faults are contained within this unit, some of which have propagated through to the top of the succession and form a horst and graben structure (Fig. 3).

\section{(D) Messinian Evaporites}

The Messinian Evaporite succession within this deep basinal region of the Eastern Mediterranean is thought to have been deposited over a period of 60 kyrs (5.6 Ma $-5.54 \mathrm{Ma}$ ) during the MSC (5.97 $\mathrm{Ma}-5.33 \mathrm{Ma}$ ) and reaches thickness $>1 \mathrm{~km}$ within the study area (Fig. 3) (Roveri et al., 2016). Beyond the study area, the Messinian Evaporites thickness varies to up to $3 \mathrm{~km}$ to the northwest and thins towards the Nile Delta in the southeast where the unit pinches out, resulting in a wedge shape geometry (Fig. 2C).

The basal bounding surface of the Messinian Evaporites is exhibited as a high amplitude soft reflection referred to as Horizon $\mathrm{N}$ (Fig. 3). It is regionally correlatable and demarcates the onset of evaporite deposition within the deep basins of the Eastern Mediterranean 5.6 Ma (Roveri et al., 2016). The upper bounding surface of the succession is defined by a high amplitude and regionally continuous hard reflection known as Horizon M (Fig. 3) which delimits the end of the MSC at 5.33 Ma (CIESM, 2008; Roveri et al., 2016).

The seismic facies of the Messinian Evaporites is predominantly opaque to discontinuous (Fig. 3), which is typical of halite rich evaporitic sequences (Bertoni and Cartwright, 2006; Feng et al., 2016). In some areas, intra salt reflectors are well imaged, suggesting local heterogeneity in the evaporitic 
stratigraphy (Fig. 3). These internal reflections most likely represent thin clastics by analogy with recent drilling results from the nearby Levant Basin (Feng et al., 2016).

\section{(D) Post-Salt Unit}

The Post-Salt Unit comprises all sediments deposited after the end of the MSC (Pliocene to Recent) and extends from Horizon $M$ to the seafloor (Fig. 3). The succession is mainly composed of highly coherent and laterally continuous reflections (Fig. 3). This seismic facies is typical of hemipelagic deposits, similar to those of the same age documented in the Levant Basin (Dolson et al., 2005; Bertoni and Cartwright, 2006). The southwest of the study area is deformed by numerous thin skinned growth faults and a well-developed channel/levee complex is evident at the seafloor within the northeast of the study area (Fig. 2B).

The most remarkable characteristic of this sedimentary unit is the prolific mud volcanism (Fig. $2 \mathrm{~B}$ and Fig. 4). The seafloor is populated with numerous mud cones and a prominent $8 \mathrm{~km}$ wide subcircular seafloor depression known as the Menes Caldera (Fig. 2B), described previously as an active area of fluid escape and mud volcanism (Huguen et al., 2009; Giresse et al., 2010; Dupré et al., 2014; Mascle et al., 2014; Pierre et al., 2014).

\section{(B) DATA AND METHODS}

The data used for this study consists of a pre-stack time migrated and pre-stack depth migrated 3D seismic cube that covers an area of $\sim 4300 \mathrm{~km}^{2}$ (Fig. 2B). The data is zero phased with SEG normal polarity, i.e. an increase in acoustic impedance is represented by a positive amplitude response. The binset dimensions of $12.5 \times 6.25 \mathrm{~m}$ yield a lateral resolution of c. $25 \mathrm{~m}$ throughout the Post-Salt Unit. This enables the identification and analysis of the varied geometry and seismic character of a large 
number of both mud volcanoes and their conduits within this succession. The dominant frequency, vertical seismic resolution and $p$-wave velocity varies with depth from one succession to another. Dominant frequency decreases from $60 \mathrm{~Hz}$ within the Post-Salt Unit to $35 \mathrm{~Hz}$ in the Messinian Evaporite succession and respective vertical seismic resolutions of $\sim 8 \mathrm{~m}$ and $\sim 30 \mathrm{~m}$ were calculated for these two intervals, using average $p$-wave velocities of $1800 \mathrm{~m} / \mathrm{s}$ and $4400 \mathrm{~m} / \mathrm{s}$ (Fig. 3).

Dimensional parameters (diameter and height) for MVCs were interpreted where they were reliably resolved within the seismic data and calculated using both pre-stack time migrated and prestack depth migrated data. The height was measured based on the minimum conduit height resolvable from the seismic data, therefore from the base of the evaporite succession to the mud cone at the upper surface of a mud volcano. The diameter is recorded as the distance from one lateral margin of a conduit to the other and is given as an average of measurements taken at a number of intersections along a single conduit using arbitrary profiles extracted from the seismic cube.

\section{(B) RESULTS}

\section{(C) DISTRIBUTION AND SEISMIC EXPRESSION OF MUD VOLCANOES}

386 individual mud volcanoes have been identified and mapped using the 3D seismic data in the study area (Fig. 2B). The average spatial density of c. 9 mud volcanoes $/ 100 \mathrm{~km}^{2}$ within the seismic survey is relatively high when compared to other densely populated mud volcano provinces including Azerbaijan or offshore Barbados where recorded densities are c. $<1 / 100 \mathrm{~km}^{2}$ (Yakubov et al., 1971; Brown and Westbrook, 1988; Milkov, 2000). The mud volcanoes are distributed throughout the PostSalt Unit at various burial depths, from just above Horizon M, to the present day seafloor (Fig. 4). This distribution is in part related to thickness change of the Post-Salt Unit within the study area (ranging from $425 \mathrm{~m}$ to $1150 \mathrm{~m}$; increasing in thickness to the East) but more importantly due to numerous phases of mud volcanism over the last $\sim 5.3$ Myrs, which as discussed by Kirkham et al. (2017) implies 
the potential for long lived overpressure within the mud source region in associated with the MSC and conceivably further elevation of overpressure due to hydrocarbon generation. They are spatially clustered in the central region of the study area (c. 15 mud volcanoes/100 $\mathrm{km}^{2}$ ), with decreasing frequency to the south-west in a growth faulted region (c. 1 mud volcano/100 km²) and to the northeast within an area dominated by a modern day channel/levee system (c. 1 mud volcano/100 km²) (Fig. 2B). The controls on the distribution of these mud volcanoes remain relatively enigmatic, with no obvious correlation between the location of mud volcanoes and seismically imaged reflection geometries, thickness variation or structural features within either the Messinian Evaporites or PreSalt Unit (Kirkham et al., 2017).

The identification of mud volcanoes within this 3D seismic volume is relatively straightforward given their distinctively lensoid geometries (Fig. 5). They typically exhibit inverted conical or conical geometry (Fig. 5A), and are easily identifiable on vertical and horizontal variance slices that exhibit an increase in discontinuity within an edifice relative to the host succession and a circular to sub-circular shape in planform (Fig. 5C and Fig. 5D). Importantly, these bodies thin towards their lateral margins and exhibit a crudely bilateral symmetry, with maximum thickness developed centrally often coincident with a conical crest at the upper bounding surface (Fig. 5A and Fig. 5B). Morphometics and volumetrics of the mud volcanoes have been documented by Kirkham et al. (2017), with heights ranging from c. $25 \mathrm{~m}$ to c. $510 \mathrm{~m}$, diameters from c. $550 \mathrm{~m}$ to c. $5660 \mathrm{~m}$, and volumes that range from as little as c. $0.1 \mathrm{~km}^{3}$ to $3.3 \mathrm{~km}^{3}$. Their upper and lower bounding reflections are high amplitude and continuous, whereas their internal seismic facies is generally chaotic to discontinuous, low frequency/low amplitude, contrasting markedly with the high amplitude/continuous seismic facies of their host succession (Fig. 5A). These seismic characteristics are consistent with documented examples of mud volcanoes from other sedimentary basins (Fowler et al., 2000; Dimitrov, 2002; Evans et al., 2007). 


\section{(C) SEISMIC EXPRESSION OF MUD VOLCANO CONDUITS}

The interpretation of the MVCs is complicated by a number of imaging artefacts associated with migrating vertical objects into their correct positions, and with transmission artefacts linked to abrupt lateral velocity changes (Løseth et al. 2011; Cartwright and Santamarina, 2015). Consequently only 93 MVCs of the 386 mud volcanoes mapped in the study area are clearly resolved within the seismic data and interpretable. The description and analysis undertaken here focuses on their geometry, and the seismic expression of the MVCs and their host sequences.

The upper terminus of the interpreted MVCs is located at the base of the mud volcano, and in some cases can be traced into the main body of the volcano, crossing the central, thickest portion aligned with a mud cone at the centre of its upper surface (e.g. Fig. 6A). In seismic profile and horizontal intersection the defining acoustic appearance is that of a vertical to sub-vertical zone of discontinuous reflections, disrupted and attenuated seismic signal, low amplitude relative to the host succession, and even complete loss of coherency (Fig. 6A and Fig. 6C). The high amplitude/continuous seismic facies of the host succession has a significant impact on the acoustic expression and ease of interpretation of the MVCs (Fig. 6). The MVCs are readily interpretable from variance profiles and slices, where they are commonly seen as strikingly circular to elliptical anomalies of high variance with sharply definable lateral margins (Fig. 6B and Fig. 6D). Interpretation of successive variance slices through the volume allows the three-dimensional geometry to be interpreted, but imaging artefacts nonetheless need to be recognised and filtered from the final geometrical interpretation. In all cases, the MVCs can be traced downwards with confidence through slices within the Post-Salt Unit to the level of Horizon M (Fig. 7 and Fig. 8).

The evaporite succession contrasts with the Post-Salt Unit in that it comprises a predominantly low amplitude and discontinuous seismic facies with a low signal to noise ratio (Fig. 3). Data quality within the Messinian Evaporites and Pre-Salt Unit becomes progressively poorer due to increasing depth and the challenges of imaging within and beneath salt (O'Brien and Gray, 1996; 
Muerdter and Ratcliff, 2001). Identifying disruption or true breaks in the continuity of reflections within the evaporites that would be diagnostic of a MVC in a similar way to as is evident within the Post-Salt Unit is therefore significantly more challenging (Fig. 6A). The discontinuous seismic facies renders variance data almost ineffectual for imaging a conduit within the succession since there is no differentiation between discontinuities related to a conduit and those associated with the mobile salt (Fig. 6B). Interpreting the geometry of MVCs within the Messinian Evaporites is therefore far more uncertain than in the highly stratified Post-Salt Unit. The interpretation of the deeper continuation of the MVCs below Horizon M is discussed in detail in the next section.

\section{(C) THE 3D GEOMETRY OF MUD VOLCANO CONDUITS}

Four representative MVCs are described in detail along with their overlying mud volcanoes to illustrate the range of geometries and contexts observed within the study area, and to illustrate further the interpretational techniques used to define their geometry. The first three examples illustrate the complicating factors that make the interpretation of the conduits within the salt so challenging. The fourth example was chosen because it contrasts with the first three in being one of the few MVCs that can be confidently interpreted through the Messinian Evaporites to the Pre-Salt Unit.

(D) MVC1

MVC1 is relatively well imaged as a vertical, crudely cylindrical zone of almost total loss of reflection coherency, overlain by a classically bilaterally symmetric volcanic cone buried beneath about $100 \mathrm{~m}$ of Late Pleistocene-Recent sediments (Fig. 7A). A well developed central crater is evident at the crest of the volcano, and is positioned directly above the MVC. The MVC is clearly identifiable through the Post-Salt Unit, but is much harder to trace downwards into the Messinian Evaporites. Here, the 


\section{Kirkham, J. Cartwright, C. Hermanrud, C. Jebsen}

imaging is less precise, and the putative downward extension of the MVC is only indicated by a broader zone of amplitude anomalies, uncollapsed diffractions and 'trails' of coherent noise that persist through the salt layer and below Horizon N. The position of MVC1 is directly above the axis of a prominent depression at Horizon N. The planform of the MVC is remarkably consistent with a slight ellipticity in a NW-SE axis on its passage through the Post-Salt Unit and with a slight narrowing downwards towards Horizon M with an average diameter of $250 \mathrm{~m}$ (Fig. 7D).

(D) MVC2

This conduit has an average diameter of $300 \mathrm{~m}$ and terminates at a mud volcano that was erupted at the present day seafloor (Fig. 7B). Internally, the volcano exhibits clear stratification and a localised strongly amplified and soft anomaly that lies immediately beneath a well developed crater at the seafloor (Fig. 7B). Beneath this, MVC2 can be traced downwards through the Post-Salt Unit to the level of Horizon M with confidence, as a zone of pronounced loss of coherence. Beneath Horizon $\mathrm{M}$, as with MVC1, the conduit is much harder to trace as the narrow zone marked by loss of coherency above gives way to a broader zone of a trail of imaging artefacts. This trail persists downwards to a prominent offset of Horizon $\mathrm{N}$, but it is not clear if this is due to a fault or due to imaging artefacts. Within the well imaged portion above Horizon $\mathrm{M}$, the planform ranges from circular to sub-circular and its planform area is greatest towards the base of the structure and progressively decreases towards the surface (Fig. 7E). There is very little lateral variation in the position of the margins of the conduit with height, which results in a structure that is almost perfectly vertical (Fig. 7B and Fig. 7E). 
(D) MVC3

This conduit is almost twice as wide as MVC1 and MVC2, but is similar to MVC2 in that it terminates upwards in a mud volcano at the seafloor but in this case one with a more subdued upper bounding surface (Fig. 7C). MVC3 can be traced downwards through the Post-Salt Unit not so much by the loss of coherence in the host reflectivity as with the previous two examples, but more by the downward deflected geometry of some of the stronger host reflections. At least one of these appears to be continuous across the conduit, but this may be artefactual. As with MVC1 and MVC2, the downward continuation into the Messinian Evaporites is concealed within a zone of seismic artefacts. Above Horizon $\mathrm{M}$, the planform is remarkably circular and the axis is almost perfectly vertical with a slight reduction in diameter upwards (Fig. 7F).

(D) MVC4

The seismic response of an MVC within the salt is most clearly illustrated in the example of MVC4 (Fig. 8). The mud volcano fed by this conduit is partially buried beneath a thin veneer of onlapping sediments close to the modern seafloor reflection onto its mud cone, which has built relief similar to MVC1 and MVC2 but lacks a central depression (Fig. 8A). Within the Post-Salt Unit the MVC exhibits a similar seismic expression to the previously described examples and is comparatively narrow (Fig. 8A and Table 1). The RMS amplitude profile (Fig. 8B) shows the margins of the conduit quite sharply contrast with the host interval particularly beneath the MTD. This profile and the slices shown in Fig. 8C-F, clearly demonstrates the pipe-like geometry that is vertical, albeit with slightly variable diameter. Some of this variation seems to correlate with the host seismic facies. Notably, the downward continuation of the pipe structure beneath Horizon $M$ is strongly suggested by the continuity of the feature in the amplitude profile, that derives from the narrow column of amplitude anomalies within the salt body (Fig. 8B). Interestingly, this extends downwards to a series of small 


\section{Kirkham, J. Cartwright, C. Hermanrud, C. Jebsen}

offsets in basal salt reflections, and coincides precisely with a crestal geometry of Horizon N. The similarity in the horizontal RMS amplitude intersections showing the planform of the pipe-like structure across both the Post-Salt Unit and Messinian Evaporites (Fig. 8C-F) further supports the interpretation of a single columnar-like structure that transects the entire post-Horizon $\mathrm{N}$ interval, and therefore connects a putative source interval in the Pre-Salt Unit, with the mud volcano at the seabed.

\section{(C) FLUID ESCAPE PIPES}

In addition to containing a large number of mud volcanoes this study area is also host to numerous fluid escape pipes (FEPs) that are distributed throughout the Post-Salt Unit. The distribution of the FEPs is similar to that of the mud volcanoes with the majority located within the central region of the study area (74 FEPs) with the remainder located within the growth fault domain (20 FEPs) and the channel/levee complex (19 FEPs). These are interpreted using the same methods used for the MVCs. They are invariably expressed on the vertical profiles as vertical columns of disruption, discontinuity and attenuation within the Post-Salt Unit, and as columns of disruption and amplification within the Messinian Evaporites. In the example presented in Figure 9, the pipe is clearly visible through the postHorizon $\mathrm{M}$ interval as a loss of coherence and continuity, that terminates upwards into a pronounced pockmark crater just below the modern seabed. Within the salt, the downward continuation of the pipe is suggested by the narrowly distributed trail of amplitude anomalies that passes downwards into a columnar disruption of intra-salt reflections (Fig. 9A). The variance profile shows a strikingly well defined column of low variance within the Post-Salt Unit, but a broader zone of low variance within the salt (Fig. 9B). The overall seismic expression of this FEPs is strikingly similar to the MVC shown in Figure 8, where it was interpreted that MVC4 extended into the Pre-Salt Unit. It seems reasonable to infer the same source region in the Pre-Salt Unit for this FEP too, based on the seismic evidence, with the only difference between the MVC and the FEP shown in Figure 8 and Figure 9 being at their upper terminus, rather than in the deeper roots. 
The seismic character and geometry of the FEPs that are observed in the study area to terminate in buried or surface pockmark craters is in all respects comparable to those exhibited by other documented examples of FEPs worldwide (Hustoft et al., 2007; Moss and Cartwright, 2010; Løseth et al., 2011). However, in compiling a catalogue of seismic expression of these FEPs, we observed a spectrum in the characteristics of the upper termini, with a range of morphological expression at the seabed at the time the FEPs evidently formed (c.f. Cartwright and Santamarina, 2015).

Four examples of pipe like structures demonstrate this spectrum of surface morphologies (Fig. 10). They appear to emanate from crestal structures at $\mathrm{N}$ and transect the Messinian Evaporites and the Post-Salt Unit (Fig. 10). A seabed pockmark is observed at the upper terminus of the example shown in Figure 10A, whereas the example in Figure 10B, shows a seabed pockmark that has been partially filled. The next two examples show upper termini that have the form of near seabed pockmarks that are overlain by surface mud volcanoes of increasing size and relief at the seafloor (Fig. $10 \mathrm{C}$ and Fig. 10D).

In summary, the FEPs observed in the study area evidently form one end of a spectrum of conduits that appear to be rooted in the Pre-Salt Unit. The morphological spectrum of upper termini shown in Figure 10, points to a direct affinity in the process leading to their formation with that for the MVCs in the study area. This point is addressed further in the Discussion.

\section{(C) SUMMARY}

The main observations derived from the 3D seismic interpretation presented in the previous sections can be summarised as follows:

1. The seismic data clearly image the MVCs within the Post-Salt Unit, from their upper terminations in the centres of mud volcanoes downwards to the level of Horizon M. 
2. All the well imaged conduits conform to a crudely cylindrical, vertical, pipe-like structure, with modest variations in diameter with height, and subtle variations in planform from circular to slightly elliptical.

3. MVCs are much harder to define beneath Horizon M both as regards their geometry, and their downward continuation. There is only limited evidence from the seismic for the locations of the root zones of the MVCs because it is so difficult to differentiate trails of imaging artefacts from true disruption of the host evaporites. This is not surprising, given the well-known problems of imaging within salt, and the generally low signal to noise ratio within the salt. Similar problems in determining the root zones of FEPs are well recognised, even when they are hosted in highly reflective clastic sequences (Cartwright and Santamarina, 2015).

4. The MVCs can be shown to represent one end of a spectrum of fluid escape conduits within the study area. The other end of the spectrum is represented by pipe-like structures terminating upwards in pockmark craters, and intermediate cases are pipes that terminate in filled pockmarks or filled pockmarks overlain by small mud cones. This spectrum is highly suggestive of a process continuum, in which the initial or immature stage is represented by the pipe terminating in a pockmark, and the more evolved stages are represented by pipes terminating in mud cones of increasing size. The possibility of this type of evolutionary process has been suggested previously (Cartwright, 2007; Huuse et al., 2010; Cartwright and Santamarina, 2015), but has not been previously supported by documented examples sampling different stages of the process in the same time interval in the same area.

\section{(B) DISCUSSION}

The lack of conclusive seismic evidence for the root zones of the pipe-like conduits terminating in either pockmarks or mud volcanoes means that a key question still to be resolved is the source of the fluids and mud that was transported via these conduits. The other more fundamental questions, that 
stem from the observations listed above, is why the conduits are cylindrical or pipe-like, and how did they form?

\section{(C) CONDUIT ROOT ZONE}

The lack of seismic constraints on the root zones as noted above means that other forms of evidence are needed to resolve the question of the source of the fluids and mud transported by the conduits. As noted briefly in the introduction, numerous documented lines of evidence based on 2D and 3D seismic studies, near-bottom investigation techniques, swath acoustic data and direct sampling from mud volcanoes at the seabed all point to a conclusion that the source of the fluids and mud in the study area is within the Pre-Salt Unit (Giresse et al., 2010; Dupré et al., 2014; Mascle et al., 2014; Kirkham et al., 2017). Of these, the most direct evidence for a Pre-Salt source in our study area comes from piston core samples from mud volcanoes currently at the seafloor which contain xenolithic clasts that are up to Cretaceous in age (Giresse et al., 2010; Dupré et al., 2014; Mascle et al., 2014). In addition, but less directly, gas samples seeping from these mud volcanoes were found to be mainly thermogenic with very high maturity indicative of a deep Pre-Salt source (Prinzhofer and Deville, 2011; Pierre et al., 2014). More indirect evidence for the Pre-Salt origin of the mud slurry comes from hot saline brine pools on the seabed within craters at the summit of the modern mud volcanoes that have been attributed to dissolution of Messinian Evaporites by fluids sourced from the Pre-Salt Unit (Huguen et al., 2009; Giresse et al., 2010; Dupré et al., 2014; Mascle et al., 2014). More widely in the region, but outside the study area, seismic evidence of mud volcanoes have also previously been interpreted to have potentially bypassed the thick salt unit (Netzeband et al., 2006; Reiche et al., 2014; Bertoni and Cartwright, 2015). It seems reasonable therefore, given this direct and contextual evidence, that the 386 mud volcanoes mapped in the study area, having erupted from the early Pliocene to the present day, have all been sourced from the Pre-Salt Unit. This in turn implies, that conduits of some unknown geometry must transect the Messinian Evaporites, and must lie obscured 


\section{Kirkham, J. Cartwright, C. Hermanrud, C. Jebsen}

on the seismic data within the distributed sub-vertical zones of artefacts and anomalous amplitudes beneath their more precisely defined upward continuations above Horizon M.

It is important to note that we cannot exclude the possibility of shallower sources of fluid and mud for the mud volcanoes, but that we consider these sources unlikely to have been significant. Sources within the Post-Salt Unit are unlikely because many of the mud volcanoes were erupted soon after the end of the MSC, when early Pliocene sediments would only have been buried tens to at most a few hundred metres. It is difficult to envisage a mechanism for the development of the extensive and sustained hard overpressure conditions that would be necessary for mud remobilisation sourced from the Post-Salt Unit over the last $\sim 5.3 \mathrm{Myrs}$, and there is no evidence for the formation of depletion zones associated with mud withdrawal within this succession (Brown, 1990; Kopf, 2002). Sources within the evaporites are more plausible, given that early sealing of any interbedded clastics might have preconditioned them for later remobilisation. Interbedded clastics have been inferred within the Messinian Evaporites based on intra-salt reflectivity (e.g. Bertoni and Cartwright, 2006), and recently proven by drilling to consist of thin layers of claystone a few meters thick (Feng et al., 2016). Although there is some intra-salt reflectivity within the study area (e.g. Fig. 3 and Fig. 4), the reflections are of limited lateral extent and continuity, in marked contrast to those calibrated by Feng et al. (2016), which extend with a continuous seismic facies for many tens or hundreds of kilometres. Localised pockets of high pressure pore fluids within the salt may have contributed to the observed mud volcanism. Possible sources of fluids within the evaporites could be linked to diagenetic transformations of gypsum into anhydrite and or carnallite into sylvite, which possess the potential to release a significant quantity of brines that could result in a volume increase of up to $40 \%$ and the development of overpressure (Jowett et al., 1993; Testa and Lugli, 2000; Eruteya et al., 2015; Bertoni and Cartwright, 2015). However such localised fluid sources, while a viable fluid source for FEPs, would seem very unlikely to have the potential to be the primary source and driver for the mud volcanism, and would not in any case explain the occurrence of the pre-Miocene clasts in present day mud volcanoes recovered in piston cores (Giresse et al., 2010; Dupré et al., 2014; Mascle et al., 2014). 


\section{(C) CONDUIT GENESIS}

An important discussion point noted above which may have important implications for any discussion of the genesis of MVCs, is the similarity in the seismic expressions of MVCs and FEPs (compare Fig. 6 and Fig. 9). These observations could indicate that the early stages of MVC formation are perhaps very similar to the formation of FEPs. This supports previous suggestions that MVCs are an evolutionary result of a FEP that has progressively incorporated an increasing amount of fine grained sediment into the composition of the migrating fluid (Cartwright, 2007; Huuse et al., 2010; Cartwright and Santamarina, 2015). Close to the FEP the sediments have a vertical stress that is the weight of the overburden, but the vertical stress within the fluid filled pipe is less once the main movement has ceased. This contrast in vertical stress over a short distance would cause the walls of an overpressured mud layer to collapse and liquefy, resulting in depletion of the layer as liquefaction progresses outward from the pipe.

With regards to the buried pockmarks (Fig. 9) within the study area, if sourced from the PreSalt Unit like the examples in Figure 10, some pipes could be considered as failed MVCs that were perhaps not successful in incorporating sufficient fine grain sediment within the migrating fluids. Fluids feeding these pipes could be sourced from permeable rocks or expelled from mudrocks but at very slow velocities that prevent movement as a mud slurry, resulting in the formation of a FEP rather than a MVC. Any model for the formation of the MVCs should therefore account for the spectrum of observed conduits and their upper terminations (Fig. 10). In the study area, by combining seismic and other more direct evidence, the most likely root zones for the pipe-like conduits for fluids or for a mud slurry are within the Pre-Salt Unit. Any physical model thus needs to explain the well-defined cylindrical geometry of both types of conduit within the clastic Post-Salt Unit, as well as a relatively high flux passage through a $>1000 \mathrm{~m}$ thick evaporite sequence that would normally be considered as being a highly effective barrier to vertical fluid migration, including for hydrocarbons (Downey, 1984). 
C. Kirkham, J. Cartwright, C. Hermanrud, C. Jebsen

We considered two main mechanisms for the formation of the spectrum of pipe-like fluid/mud conduits in the study area, based on a review of previous studies on MVCs and FEPs, balanced with the key observations listed at the beginning of this discussion. These two mechanisms are (1) natural hydraulic fracturing under extreme overpressure generated within the Pre-Salt Unit, and (2) dissolution-stoping ascent of hot undersaturated pore fluids liberated from overpressure cells within the Pre-Salt Unit.

\section{(D) Hydraulic fracturing}

The genesis of pipe-like structures linked to highly focused fluid escape (fluid escape pipes) has been widely argued to result from catastrophic breaching of top seals in a highly dynamic process involving hydraulic fracturing under elevated pore fluid pressures (Cartwright et al., 2007; Hustoft et al., 2007; Hustoft et al., 2010; Moss and Cartwright, 2010; Løseth et al., 2011; Davies et al., 2012; Cartwright and Santamarina, 2015). By analogy, and bearing in mind the need to account for the similarity between MVCs and FEPs in the study area, it seems reasonable to invoke a similar process to explain the propagation upwards of MVCs through both the Messinian Evaporites and the Post-Salt Unit.

A number of previous studies have suggested that hydraulic fracturing plays a crucial role in the formation of pipe-like MVCs, and envisage the pipe structure as consisting of a network of fractures that have propagated to the surface within a vertical cylindrical zone (Morley, 2003; Stewart and Davies, 2006). Field studies have documented exhumed mud volcano feeder systems and shown them to comprise complex fracture zones containing mud and clasts of country rock, with strong evidence for vertical fluid and mobile sediment intrusion through fracture networks (Fig. 1D) (Morley et al., 1998; Clari et al., 2004; Roberts et al., 2010; Cartwright and Santamarina, 2015). The fracture density within these conduits gradually increases towards its centre, eventually forming a highly fractured columnar zone at the centre of the conduit, where higher mud flow is localised (Fig. 1D) 
(Roberts et al., 2010). In the absence of any direct evidence for a hydraulic fracturing mechanism for pipe formation (Cartwright and Santamarina, 2015), the exhumed MVCs described by Roberts et al. (2010) present the best current analogue for the development of cylindrical regions of hydraulic fractures within MVCs.

Hard overpressure is a critical precondition for the formation of hydraulic fractures within a sedimentary basin and is widely considered to drive the ascent of mud and pore fluids from deeper sedimentary layers during the formation of mud volcanoes (Brown, 1990; Osborne and Swarbrick, 1997; Dimitrov, 2002; Morley, 2003). So can it be argued that sufficient conditions of regionally extensive hard overpressure (fluid pressure approaching the lithostatic pressure) existed in the putative Pre-Salt source region supplying mud and fluids up the propagating conduits and providing the necessary energy for continued hydraulic failure?

The MSC has been invoked to have had a major influence on the development of overpressure in the Pre-Salt, made evident by various fluid flow related features including mud mobilisation, cold seeps and pockmark formation and shallow laccolith intrusion (Pierre et al., 2002; Bertoni et al., 2013; Bertoni and Cartwright, 2015). Rapid loading of Pre-Salt sediments by a c. > $1 \mathrm{~km}$ succession of low permeability evaporites poses the potential for wide spread high fluid retention, undercompaction and a vertical direction of maximum compressive stress, resulting in overpressuring of the Pre-Salt Unit (particularly the immediate Pre-Salt) (Osborne and Swarbrick, 1997; Bertoni and Cartwright, 2015). The lateral extent and sealing capacity of the evaporite succession presents the potential for a significant and long lasting overpressured system within the Pre-Salt Unit. Low level fluctuations in pore-fluid pressure are likely all that is required in order for overpressure to locally exceed lithostatic pressure, potentially resulting in localised uplift of the base seal and formation of an initial fracture (Fig. 11A). Potential mechanisms for dynamic fluctuations in pore fluid pressure include earthquakes (Tanikawa et al. 2010), rapid loading or unloading by eustatic changes (Hermanrud et al., 2013), lateral 


\section{Kirkham, J. Cartwright, C. Hermanrud, C. Jebsen}

compression and shearing associated with boundary friction at the salt/Pre-Salt interface as a result of movement of mobile evaporites (Hudec and Jackson, 2007).

An alternative source of overpressure in the Pre-Salt Unit could have come in the form of hydrocarbon generation. Methane is considered almost ubiquitous in the eruption of modern mud volcanoes and also many FEPs (Kopf, 2002; Cartwright and Santamarina, 2015). The generation and accumulation of hydrocarbons present an effective mechanism to build-up further pore fluid pressure within an already overpressure Pre-Salt (Hedberg, 1980; Charlou et al., 2003; Dimitrov, 2002; Kopf, 2002). Mesozoic and Oligocene source rocks recently documented within the deep water region of the Nile Delta and methane-rich and oily hydrocarbon-rich hot brine and mud samples taken from several mud volcanoes within this study area indicate the presence of hydrocarbons within the migrating mud slurry (Aal et al., 2000; Vandré et al., 2007; Huguen et al., 2009; Dupré et al., 2014; Pierre et al., 2014). As stated above, seepage samples from mud volcanoes within this region are mainly thermogenic, highly mature and sourced from beneath the evaporite succession (Prinzhofer and Deville, 2011; Pierre et al., 2014). The presence of Pre-Salt hydrocarbon plays are therefore evident within this region and possess the potential to have a profound impact on Pre-Salt pore fluid pressure and effective stress.

A key question within this basin is do hydraulic fractures form and propagate across a c. $>1$ $\mathrm{km}$ thick layer of evaporites possibly mainly composed of halite? Despite the sealing capabilities of evaporites it is thought that a network of hydraulic fractures can form within rock salt where fluids are present either within or beneath evaporites at near-lithostatic pressure (Urai et al., 2008; Warren, 2016). One possibility is if fluid pressure within the Pre-Salt source unit exceeds the tensile strength and minimum horizontal stress of the sealing overburden (Delaney et al., 1986; Cosgrove, 2001; Eruteya et al., 2015). Alternatively at sufficiently low effective mean stress, dilatancy and fracturing can also occur in a deforming salt such as the Messinian Evaporite succession, resulting in the formation of significant permeability pathways that Pre-Salt fluids could exploit (Peach and Spiers, 
1996; Urai et al., 2008; Eruteya et al., 2015). In order for high pressure fluids and entrained fine grained sediment to be injected into the evaporitic and Post-Salt Unit along hydraulic fractures, a sustained pressure differential between the fluids within the propagating intrusion and pore fluids is required in order to achieve fracture dilation (Jolly and Lonergan, 2002). The specific locations at which hydraulic fracturing initiates is difficult to explain due to poor imaging within the Pre-Salt Unit and because the original geometry of the source region of the mud volcanoes has been altered significantly by the formation of depletion zones during the withdrawal of liquefied sediment (Kirkham et al., 2017). However, FEPs and early stage MVCs are observed positioned above crestal structures at the base of the evaporites, which strongly favours the formation of a conduit due to lateral pressure transfer and crestal leakage, prior to reconfiguration of the base-salt geometry during the formation of a depletion zone (Fig. 10).

\section{(D) Dissolution and stoping}

The process of dissolution can result in localised subsurface volume loss of a substrate and has been known to lead to later collapse of the overburden within a columnar zone, forming a structure defined as a dissolution pipe (Sun et al., 2013; Cartwright and Santamarina, 2015). These pipes are restricted to areas where there are carbonates and/or evaporites at depth. Dissolution pipes are considered to propagate upward from the locus of dissolution events. Fracturing within dissolution pipes as a result of upward propagating collapse increases permeability and can promote fluid migration within a vertical column (McDonnell et al., 2007). In contrast to the hydraulic fracturing mechanism discussed above, the process does not require overpressure.

It must be taken into account that this process would be much slower when compared to hydraulic fracturing and is self-limiting, as the volume of salt that can be taken into solution before the fluids become supersaturated is finite (Bertoni and Cartwright, 2005). Additionally this mechanism 


\section{Kirkham, J. Cartwright, C. Hermanrud, C. Jebsen}

would not be applicable within the Post-Salt Unit, however, it could be effective as a catalyst during the initial stage of conduit propagation at the base of the evaporite succession and may contribute the final geometry and internal character of the conduit (Fig. 11A). Hot saline brine pools associated with these mud volcanoes imply that dissolution could have been a factor in the formation of these conduits (Huguen et al., 2009; Giresse et al., 2010; Dupré et al., 2014; Mascle et al., 2014).

By analogy the collapse mechanism proposed here is similar to one suggested for the formation of presently outcropping mud volcano feeder complexes in Azerbaijan referred to as stoping (Roberts et al., 2010). The mechanism of stoping originates from igneous intrusions where an invading melt widens fractures and causes the overburden to disintegrate, break apart, and collapse, resulting in a slow upwards propagating process which produces a collapse pipe (Marsh, 1982). Temperatures recorded from MVCs (as little as $11^{\circ} \mathrm{C}$ to $>100^{\circ} \mathrm{C}$ ) are at least an order of magnitude less than in igneous systems $\left(>1000^{\circ} \mathrm{C}\right)$, so thermal expansion and disintegration of the host rock would generally not be considered applicable in MVCs (Roberts et al., 2010). However, dissolution within the evaporite succession and fracturing within the vertical column of the conduit could result in subsequent collapse of the host succession in a process somewhat similar to stoping.

The potential conduit forming processes described here all represent viable mechanisms for having contributed to the formation of the MVCs within this study area. The most probable explanation for their genesis is that they are formed primarily through hydraulic fracturing, with dissolution and stoping acting as contributory mechanisms during the evolution of the conduit (Fig. 11). A conceptual model of the stages for the genesis of MVCs through evaporites is presented in Figure 11. In summary the analysis presented here demonstrates the potential for MVCs to bypass thick evaporite successions and to vertically transport significant volumes of fluid and sediment over great distances through 'sealing' salt sequences. These findings should not be regarded in isolation since they have significant implications with regards to breaching of Messinian Evaporite seals in other regions of the Mediterranean, and more generally of thick evaporitic seals in salt basins worldwide. 


\section{(B) CONCLUSIONS}

This study has presented an analysis of the seismic response and geometrical form of a large number of MVCs from offshore Egypt. The key outcome is that their interpretation and description clearly demonstrates the potential for bypassing of thick sequences of 'sealing' evaporites via focused fluid and sediment mobilisation. Further important outcomes include:

- Pipe-like MVCs can be reliably identified within 3D seismic data as vertical zones of, disruption, discontinuity and reduced seismic response, similar to the seismic expression of FEPs.

- They exhibit complex geometries ranging from vertical to sub-vertical structures that vary in planform area and shape from circular, to sub-circular, to elliptical. The resulting 3D shape ranges from cylindrical, to conical or inverted conical columns, the description of which demonstrate a more complex geometry than previously documented.

- The description of MVCs and FEPs implies that the early stages of MVCs formation is perhaps similar to the formation of FEPs. Some FEPs may evolve into MVCs with increasing fine grained sediment input and sustained overpressure within the source unit. If rooted to the same Pre-Salt sedimentary layer as the MVCs, FEPs with buried pockmarks at their upper terminus may represent failed MVCs.

- Analysis of this high resolution 3D seismic data demonstrates that MVCs can be interpreted within evaporites and inferred to root within Pre-Salt stratigraphy.

- Rapid loading due to evaporite deposition during the MSC resulted in high fluid retention, undercompaction and significant overpressuring within Pre-Salt stratigraphy. Subsequent dynamic fluctuations in pore fluid pressure via mechanisms including increasing gas pressure associated with Pre-Salt hydrocarbon plays, earthquakes, rapid loading or unloading by eustatic changes and, lateral compression and sheering associated with salt flow, could potentially lead to 
localised areas of overpressure equal to the lithostatic pressure, resulting in the formation of hydraulic fractures.

- Dissolution of the evaporites could cause localised subsurface volume loss. Fluids exploiting the newly formed hydraulic fractures may lead to further dissolution, fracturing and collapse within the conduit via a stoping mechanism. This is a slow process compared to hydraulic fracturing that could contribute to the final character of the MVC.

\section{(B) ACKNOWLEDGEMENTS}

We would like to thank Statoil for provision of the data used in this study and NERC for award number BW22003102 that supported this research. We are also grateful to Schlumberger for provision of the IESX and Petrel software suites for the seismic interpretation. We would like to thank Editor Atle Rotevatn and the reviewers Gérôme Calvès, Sarah Cobain and Henrik Svensen for their constructive feedback that helped to greatly improve the manuscript.

\section{CONFLICT OF INTEREST}

No conflict of interest declared.

\section{(B) REFERENCES}

AAL, A. A., EL BARKOOKY, A., GERRITS, M., MEYER, H., SCHWANDER, M. \& ZAKI, H. 2000. Tectonic evolution of the Eastern Mediterranean Basin and its significance for hydrocarbon prospectivity in the ultradeepwater of the Nile Delta. The Leading Edge, 19, 1086-1102.

BARBER, P. M. 1981. Messinian subaerial erosion of the proto-Nile Delta. Marine Geology, 44, 253272.

BERTONI, C. \& CARTWRIGHT, J. 2005. 3D seismic analysis of circular evaporite dissolution structures, Eastern Mediterranean. Journal of the Geological Society, 162, 909-926.

BERTONI, C. \& CARTWRIGHT, J. 2015. Messinian evaporites and fluid flow. Marine and Petroleum Geology, 66, 165-176.

BERTONI, C., CARTWRIGHT, J. \& HERMANRUD, C. 2013. Evidence for large-scale methane venting due to rapid drawdown of sea level during the Messinian Salinity Crisis. Geology, 41, 371-374. 
BERTONI, C. \& CARTWRIGHT, J. A. 2006. Controls on the basinwide architecture of late Miocene (Messinian) evaporites on the Levant margin (Eastern Mediterranean). Sedimentary Geology, 188, 93-114.

BROWN, K. \& WESTBROOK, G. 1988. Mud diapirism and subcretion in the Barbados Ridge accretionary complex: the role of fluids in accretionary processes. Tectonics, 7, 613-640.

BROWN, K. M. 1990. The nature and hydrogeologic significance of mud diapirs and diatremes for accretionary systems. Journal of Geophysical Research, 95, 8969-8982.

CALVES, G., SCHWAB, A., HUUSE, M., VAN RENSBERGEN, P., CLIFT, P., TABREZ, A. \& INAM, A. 2010. Cenozoic mud volcano activity along the Indus Fan: offshore Pakistan. Basin Research, 22, 398413.

CARTWRIGHT, J. 2007. The impact of 3D seismic data on the understanding of compaction, fluid flow and diagenesis in sedimentary basins. Journal of the Geological Society, 164, 881-893.

CARTWRIGHT, J., HUUSE, M. \& APLIN, A. 2007. Seal bypass systems. AAPG Bulletin, 91, 1141-1166.

CARTWRIGHT, J. \& SANTAMARINA, C. 2015. Seismic characteristics of fluid escape pipes in sedimentary basins: implications for pipe genesis. Marine and Petroleum Geology, 65, 126140.

CARTWRIGHT, J. A. \& JACKSON, M. P. A. 2008. Initiation of gravitational collapse of an evaporite basin margin: The Messinian saline giant, Levant Basin, eastern Mediterranean. Geological Society of America Bulletin, 120, 399-413.

CHARLOU, J., DONVAL, J., ZITTER, T., ROY, N., JEAN-BAPTISTE, P., FOUCHER, J. \& WOODSIDE, J. 2003. Evidence of methane venting and geochemistry of brines on mud volcanoes of the eastern Mediterranean Sea. Deep Sea Research Part I: Oceanographic Research Papers, 50, 941-958.

CIESM 2008. The Messinian Salinity Crisis from mega-deposits to microbiology - A consensus report. $N^{\circ} 33$ in CIESM Workshop Monographs [F. Briand, Ed.], 168 pages, Monaco.

CLARI, P., CAVAGNA, S., MARTIRE, L. \& HUNZIKER, J. 2004. A Miocene mud volcano and its plumbing system: a chaotic complex revisited (Monferrato, NW Italy). Journal of Sedimentary Research, 74, 662-676.

COSGROVE, J. W. 2001. Hydraulic fracturing during the formation and deformation of a basin: A factor in the dewatering of low-permeability sediments. AAPG bulletin, 85, 737-748.

DAVIES, R. J., MATHIAS, S. A., MOSS, J., HUSTOFT, S. \& NEWPORT, L. 2012. Hydraulic fractures: How far can they go? Marine and petroleum geology, 37, 1-6.

DAVIES, R. J. \& STEWART, S. A. 2005. Emplacement of giant mud volcanoes in the South Caspian Basin: 3D seismic reflection imaging of their root zones. Journal of the Geological Society, 162, 1-4.

DELANEY, P. T., POLLARD, D. D., ZIONY, J. I. \& MCKEE, E. H. 1986. Field relations between dikes and joints: emplacement processes and paleostress analysis. Journal of Geophysical Research: Solid Earth (1978-2012), 91, 4920-4938.

DIMITROV, L. I. 2002. Mud volcanoes--the most important pathway for degassing deeply buried sediments. Earth-Science Reviews, 59, 49-76.

DOLSON, J., BOUCHER, P., SIOK, J. \& HEPPARD, P. Key challenges to realizing full potential in an emerging giant gas province: Nile Delta/Mediterranean offshore, deep water, Egypt. Geological Society, London, Petroleum Geology Conference series, 2005. Geological Society of London, 607-624.

DOWNEY, M. W. 1984. Evaluating seals for hydrocarbon accumulations. AAPG Bulletin, 68, 1752-1763.

DUPRÉ, S., MASCLE, J., FOUCHER, J.-P., HARMEGNIES, F., WOODSIDE, J. \& PIERRE, C. 2014. Warm brine lakes in craters of active mud volcanoes, Menes caldera off NW Egypt: evidence for deeprooted thermogenic processes. Geo-Marine Letters, 34, 153-168.

ERUTEYA, O. E., WALDMANN, N., SCHALEV, D., MAKOVSKY, Y. \& BEN-AVRAHAM, Z. 2015. Intra-to PostMessinian deep-water gas piping in the Levant Basin, SE Mediterranean. Marine and Petroleum Geology.

EVANS, R. J., DAVIES, R. J. \& STEWART, S. A. 2007. Internal structure and eruptive history of a kilometre-scale mud volcano system, South Caspian Sea. Basin Research, 19, 153-163. 
FENG, Y. E., YANKELZON, A., STEINBERG, J. \& RESHEF, M. 2016. Lithology and characteristics of the Messinian evaporite sequence of the deep Levant Basin, eastern Mediterranean. Marine Geology, 376, 118-131.

FOWLER, S., MILDENHALL, J., ZALOVA, S., RILEY, G., ELSLEY, G., DESPLANQUES, A. \& GULIYEV, F. 2000. Mud volcanoes and structural development on Shah Deniz. Journal of Petroleum Science and Engineering, 28, 189-206.

GIRESSE, P., LONCKE, L., HUGUEN, C., MULLER, C. \& MASCLE, J. 2010. Nature and origin of sedimentary clasts associated with mud volcanoes in the Nile deep-sea fan. Relationships with fluid venting. Sedimentary Geology, 228, 229-245.

GRAUE, K. 2000. Mud volcanoes in deepwater Nigeria. Marine and Petroleum Geology, 17, 959-974.

HEDBERG, H. D. 1980. Methane generation and petroleum migration. AAPG Special Volumes, 10, 179206.

HERMANRUD, C., VENSTAD, J. M., CARTWRIGHT, J., RENNAN, L., HERMANRUD, K. \& BOLÅS, H. M. N. 2013. Consequences of water level drops for soft sediment deformation and vertical fluid leakage. Mathematical Geosciences, 45, 1-30.

HSÜ, K. J., MONTADERT, L., BERNOULLI, D., CITA, M. B., GARRISON, R. E., KIDD, R. B., MELIERES, F., MÜLLER, C. \& WRIGHT, R. 1977. History of the Mediterranean salinity crisis. Structural history of the Mediterranean basins, 421.

HUDEC, M. R. \& JACKSON, M. 2007. Terra infirma: Understanding salt tectonics. Earth-Science Reviews, 82, 1-28.

HUGUEN, C., FOUCHER, J. P., MASCLE, J., ONDREAS, H., THOUEMENT, M., GONTHARET, S., STADNITSKAIA, A., PIERRE, C., BAYON, G. \& LONCKE, L. 2009. Menes caldera, a highly active site of brine seepage in the Eastern Mediterranean sea:" In situ" observations from the NAUTINIL expedition (2003). Marine Geology, 261, 138-152.

HUSTOFT, S., BÜNZ, S. \& MIENERT, J. 2010. Three-dimensional seismic analysis of the morphology and spatial distribution of chimneys beneath the Nyegga pockmark field, offshore mid-Norway. Basin Research, 22, 465-480.

HUSTOFT, S., MIENERT, J., BÜNZ, S. \& NOUZÉ, H. 2007. High-resolution 3D-seismic data indicate focussed fluid migration pathways above polygonal fault systems of the mid-Norwegian margin. Marine Geology, 245, 89-106.

HUUSE, M., JACKSON, C. A. L., VAN RENSBERGEN, P., DAVIES, R. J., FLEMINGS, P. B. \& DIXON, R. J. 2010. Subsurface sediment remobilization and fluid flow in sedimentary basins: an overview. Basin Research, 22, 342-360.

JOLLY, R. J. \& LONERGAN, L. 2002. Mechanisms and controls on the formation of sand intrusions. Journal of the Geological Society, 159, 605-617.

JOWETT, E. C., CATHLES III, L. M. \& DAVIS, B. W. 1993. Predicting depths of gypsum dehydration in evaporitic sedimentary basins. AAPG Bulletin, 77, 402-413.

KIRKHAM, C., CARTWRIGHT, J., HERMANRUD, C. \& JEBSEN, C. 2017. The spatial, temporal and volumetric analysis of a large mud volcano province within the Eastern Mediterranean. Marine and Petroleum Geology, 81, 1-16.

KOPF, A. J. 2002. Significance of mud volcanism. Reviews of Geophysics, 40, 1-52.

LOFI, J., DÉVERCHÈRE, J., GAULLIER, V., GILLET, H., GORINI, C., GUENNOC, P., LONCKE, L., MAILLARD, A., SAGE, F. \& THINON, I. 2011. Seismic atlas of the Messinian Salinity Crisis markers in the Mediterranean and Black Seas. Mémoire de la Société Géologique ns, 179, 1-72.

LONCKE, L., MASCLE, J. \& PARTIES, F. S. 2004. Mud volcanoes, gas chimneys, pockmarks and mounds in the Nile deep-sea fan (Eastern Mediterranean): geophysical evidences. Marine and Petroleum Geology, 21, 669-689.

LØSETH, H., WENSAAS, L., ARNTSEN, B., HANKEN, N.-M., BASIRE, C. \& GRAUE, K. 2011. 1000 m long gas blow-out pipes. Marine and Petroleum Geology, 28, 1047-1060.

MACGREGOR, D. S. 2012. The development of the Nile drainage system: integration of onshore and offshore evidence. Petroleum Geoscience, 18, 417-431. 
MARSH, B. D. 1982. On the mechanics of igneous diapirism, stoping, and zone melting. American Journal of Science, 282, 808-855.

MASCLE, J., MARY, F., PRAEG, D., BROSOlO, L., CAMERA, L., CERAMICOLA, S. \& DUPRÉ, S. 2014. Distribution and geological control of mud volcanoes and other fluid/free gas seepage features in the Mediterranean Sea and nearby Gulf of Cadiz. Geo-Marine Letters, 34, 89-110.

MCDONNELL, A., LOUCKS, R. G. \& DOOLEY, T. 2007. Quantifying the origin and geometry of circular sag structures in northern Fort Worth Basin, Texas: Paleocave collapse, pull-apart fault systems, or hydrothermal alteration? AAPG bulletin, 91, 1295-1318.

MILKOV, A. V. 2000. Worldwide distribution of submarine mud volcanoes and associated gas hydrates. Marine Geology, 167, 29-42.

MORLEY, C. 2003. Outcrop examples of mudstone intrusions from the Jerudong anticline, Brunei Darussalam and inferences for hydrocarbon reservoirs. Geological Society, London, Special Publications, 216, 381-394.

MORLEY, C., CREVELLO, P. \& AHMAD, Z. H. 1998. Shale tectonics and deformation associated with active diapirism: the Jerudong Anticline, Brunei Darussalam. Journal of the Geological Society, $155,475-490$.

MOSS, J. \& CARTWRIGHT, J. 2010. 3D seismic expression of km-scale fluid escape pipes from offshore Namibia. Basin Research, 22, 481-501.

MUERDTER, D. \& RATCLIFF, D. 2001. Understanding subsalt illumination through ray-trace modeling, Part 1: Simple 2-D salt models. The Leading Edge, 20, 578-594.

NETZEBAND, G., HÜBSCHER, C. \& GAJEWSKI, D. 2006. The structural evolution of the Messinian evaporites in the Levantine Basin. Marine Geology, 230, 249-273.

O'BRIEN, M. J. \& GRAY, S. H. 1996. Can we image beneath salt? The Leading Edge, 15, 17-22.

OSBORNE, M. J. \& SWARBRICK, R. E. 1997. Mechanisms for generating overpressure in sedimentary basins; a reevaluation. AAPG Bulletin, 81, 1023-1041.

PEACH, C. J. \& SPIERS, C. J. 1996. Influence of crystal plastic deformation on dilatancy and permeability development in synthetic salt rock. Tectonophysics, 256, 101-128.

PICKERING, K. T., AGAR, S. M. \& OGAWA, Y. 1988. Genesis and deformation of mud injections containing chaotic basalt-limestone-chert associations: Examples from the southwest Japan forearc. Geology, 16, 881-885.

PIERRE, C., BAYON, G., BLANC-VALLERON, M.-M., MASCLE, J. \& DUPRÉ, S. 2014. Authigenic carbonates related to active seepage of methane-rich hot brines at the Cheops mud volcano, Menes caldera (Nile deep-sea fan, eastern Mediterranean Sea). Geo-Marine Letters, 34, 253-267.

PIERRE, C., ROUCHY, J.-M. \& BLANC-VALLERON, M.-M. 2002. Gas hydrate dissociation in the Lorca Basin (SE Spain) during the Mediterranean Messinian salinity crisis. Sedimentary Geology, 147, 247-252.

PRINZHOFER, A. \& DEVILLE, E. 2011. Origins of hydrocarbon gas seeping out from offshore mud volcanoes in the Nile delta. Tectonophysics.

REICHE, S., HÜBSCHER, C. \& BEITZ, M. 2014. Fault-controlled evaporite deformation in the Levant Basin, Eastern Mediterranean. Marine Geology, 354, 53-68.

ROBERTS, K., DAVIES, R. \& STEWART, S. 2010. Structure of exhumed mud volcano feeder complexes, Azerbaijan. Basin Research, 22, 439-451.

ROBERTSON, A. H. \& KOPF, A. 1998. Tectonic setting and processes of mud volcanism on the Mediterranean Ridge accretionary complex: evidence from Leg 160. Proceedings of the Ocean Drilling Program, Scientific Results, Vol. 160; Chapter 50.

ROVERI, M., GENNARI, R., LUGLI, S., MANZI, V., MINELLI, N., REGHIZZI, M., RIVA, A., ROSSI, M. E. \& SCHREIBER, B. C. 2016. The Messinian salinity crisis: open problems and possible implications for Mediterranean petroleum systems. Petroleum Geoscience, petgeo2015-089.

SESTINI, G. 1989. Nile Delta: a review of depositional environments and geological history. Geological Society, London, Special Publications, 41, 99-127. 
STEWART, S. A. \& DAVIES, R. J. 2006. Structure and emplacement of mud volcano systems in the South Caspian Basin. AAPG bulletin, 90, 771-786.

SUN, Q., CARTWRIGHT, J., WU, S. \& CHEN, D. 2013. 3D seismic interpretation of dissolution pipes in the South China Sea: Genesis by subsurface, fluid induced collapse. Marine Geology, 337, 171181.

TESTA, G. \& LUGLI, S. 2000. Gypsum-anhydrite transformations in Messinian evaporites of central Tuscany (Italy). Sedimentary Geology, 130, 249-268.

URAI, J., SCHLÉDER, Z., SPIERS, C. \& KUKLA, P. 2008. Flow and transport properties of salt rocks. Dynamics of Complex Intracontinental Basins: The Central European Basin System, 277-290.

VANDRÉ, C., CRAMER, B., GERLING, P. \& WINSEMANN, J. 2007. Natural gas formation in the western Nile delta (Eastern Mediterranean): thermogenic versus microbial. Organic Geochemistry, 38, 523-539.

WARREN, J. K. 2016. Salt usually seals, but sometimes leaks: Implications for mine and cavern stability in the short and long term. Earth-Science Reviews.

YAKUBOV, A., ALI-ZADE, A. \& ZEILANOV, M. 1971. Mud volcanoes of Azerbaijan. SSR: Atlas, Azerbaijan Academy of Science, Baku. 


\section{FIGURE AND TABLE LEGENDS}

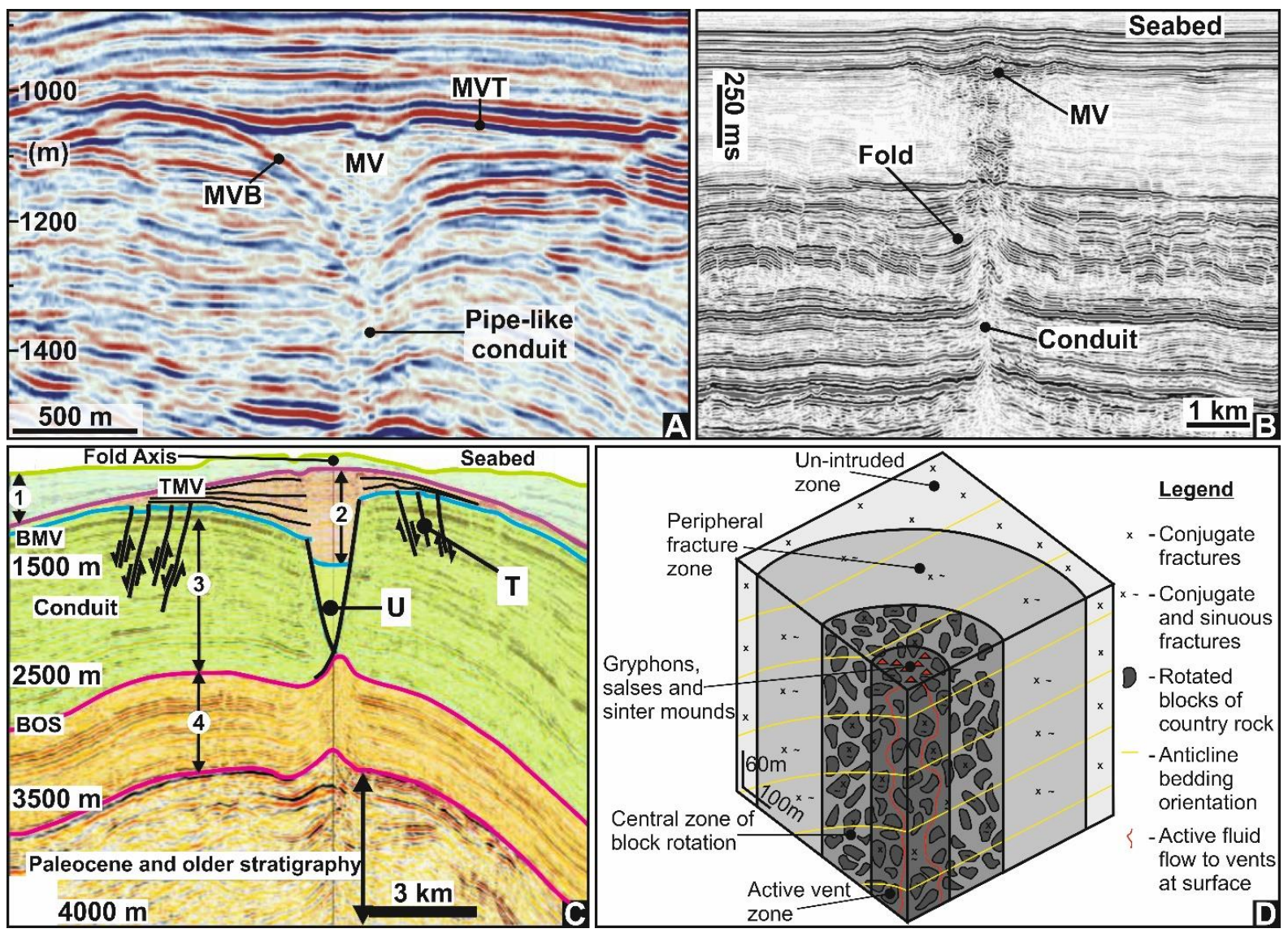

Figure 1. Documented examples of mud volcano conduits (MVCs). (A) A mud volcano with a well imaged pipelike conduit from the South Caspian Basin (Modified from Stewart and Davies, 2006). (B) A buried mud volcano with an underlying cylindrical conduit from the Gjallar Ridge, offshore mid-Norway. The conduit is associated with localized folding and vertically stacked amplitude anomalies, indicative of gas or cementation (Modified from Cartwright et al., 2007). (C) A large mud volcano and underlying feeder system from the South Caspian Basin, interpreted to have formed by fluidised mud flows through fractures. TMV - Top mud volcano; BMV Base mud volcano; T - Concentric planar normal faults; U - Downward tapering cone; BOS - Base overburden surface; 1-4 - subdivision of units (Modified from Davies and Stewart, 2005). (D) Schematic of a MVC based on exhumed field examples from Azerbaijan (Modified from Roberts et al., 2010). 


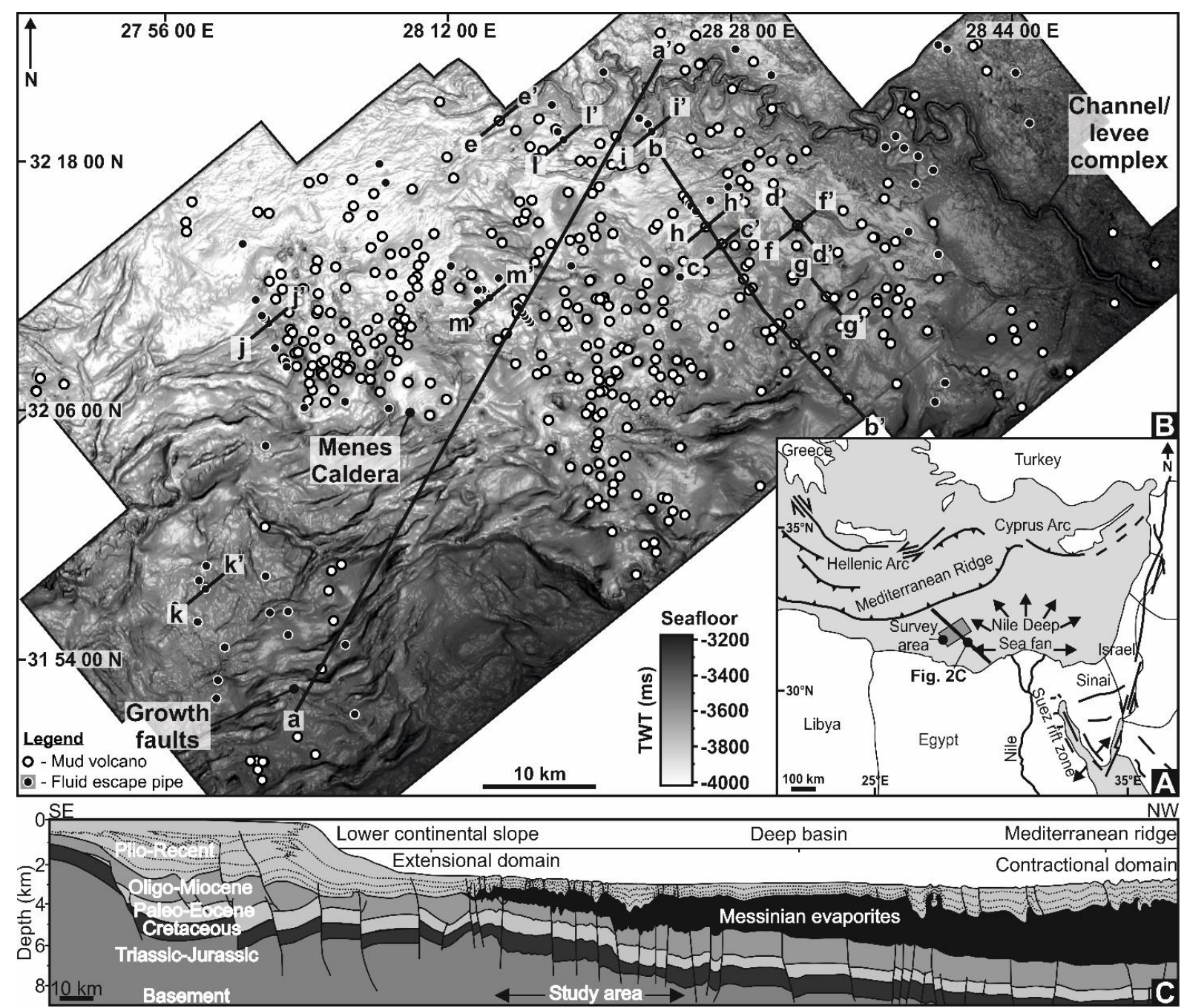

Figure 2. Geotectonic setting of the survey area. (A) Location map of the study region offshore Egypt, Eastern Mediterranean, showing the location of the three-dimensional (3D) seismic survey (grey rectangle) used within this study. (B) Seafloor map within the seismic study area showing the position of $\mathbf{1 1 0}$ mud volcanoes at the seafloor (white points with black outlines), a further 276 buried mud volcanoes (white points with black dashed outlines) and 113 fluid escape pipes (black points with white outlines), distributed within the PostSalt Unit and primarily concentrated within the central region of the study area. Highlighted on the map are prominent modern seafloor features including growth faults within the SW of the study area, a channel levee complex to the NE and the c. $8 \mathrm{~km}$ wide seafloor depression of the Menes Caldera. The lines of seismic section in Fig. 3 (a-a'), Fig. 4 (b-b'), Fig. 5 (c-c'), Fig. 6 (d-d'), Fig. 7 (e-e'; f-f'; g-g'), Fig. 8 (h-h'), Fig. 9 (i-i'), Fig. 10 (j-j'; k$\mathbf{k}^{\prime} ; \mathrm{I}-\mathrm{I}^{\prime} ; \mathrm{m}-\mathrm{m}^{\prime}$ ) are displayed. (C) Schematic cross section through the Nile delta and the 3D seismic survey area and towards the Mediterranean ridge (see Fig. 2A for line of section). The cross section shows the main stratigraphic intervals and varying salt thickness within the basin (modified from Vandré et al. (2007) and (Lofi et al. (2011)). 


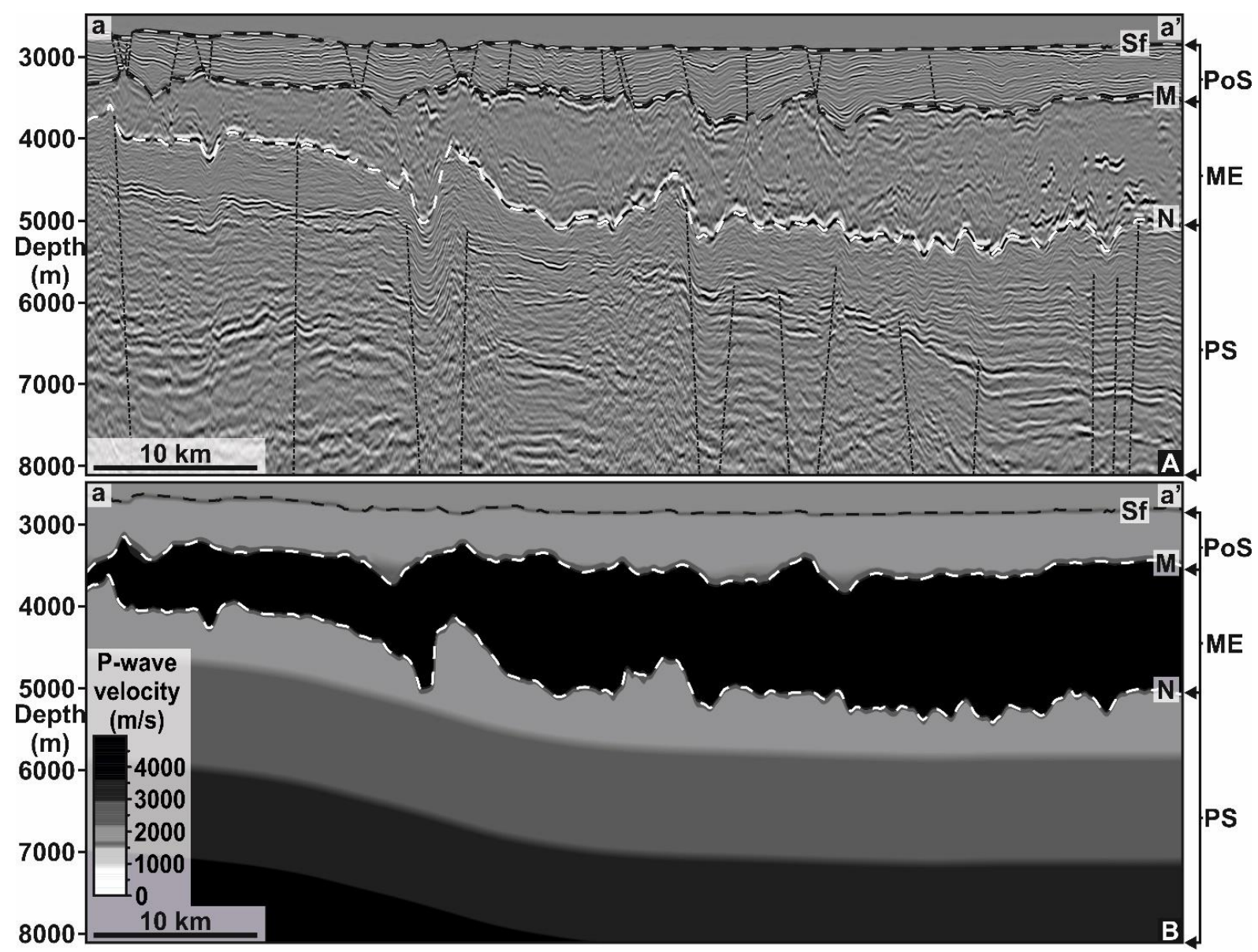

Figure 3. Seismic stratigraphy of the study area. (A) Pre-stack depth migrated seismic profile through the study area (see line a-a' in Fig. 2B for location) showing the main stratigraphic units and the wedge shape geometry of the Messinian Evaporite succession (ME). (B) Pre-stack depth migrated velocity profile through the study area (same line a-a' as in Fig. 3A) that clearly exhibits the contrast in p-wave velocity between the Messinian Evaporite succession and the Pre-Salt Unit (PS) and Post-Salt Unit (PoS). Sf - Seafloor; M - Horizon M (topsalt); $\mathbf{N}$ - Horizon $\mathbf{N}$ (base-salt). 


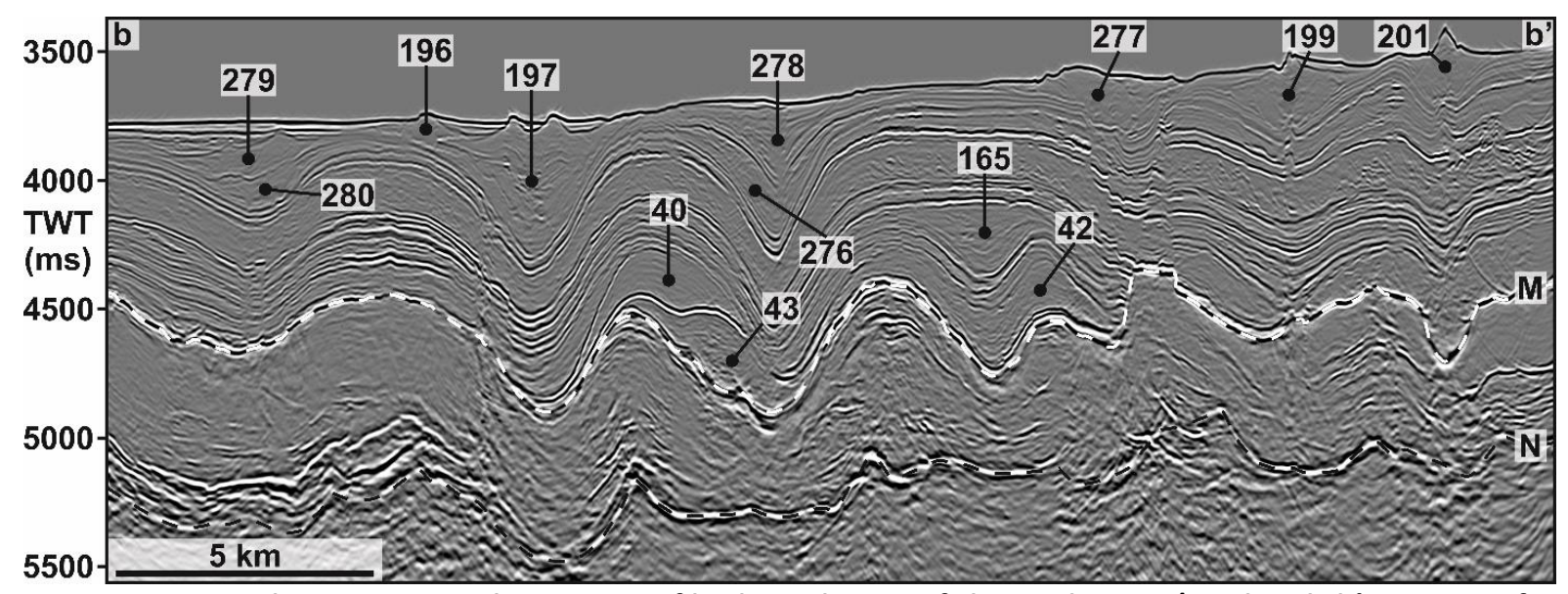

Figure 4. Pre-stack time migrated seismic profile through part of the study area (see line b-b' in Fig. 2B for location) displaying numerous mud volcanoes at various depths through the Post-Salt Unit, from just above the Messinian Evaporite succession to at the present day seafloor. The mud volcanoes are annotated with their ID number from the $\mathbf{3 8 6}$ mud volcanoes that have been interpreted. Mud volcanoes located at greater depth within the Post-Salt Unit exhibit a more deformed geometry resulting from the movement of underlying mobile substrates. $\mathbf{M}$ - Horizon $\mathbf{M}$; $\mathbf{N}$ - Horizon $\mathbf{N}$. 

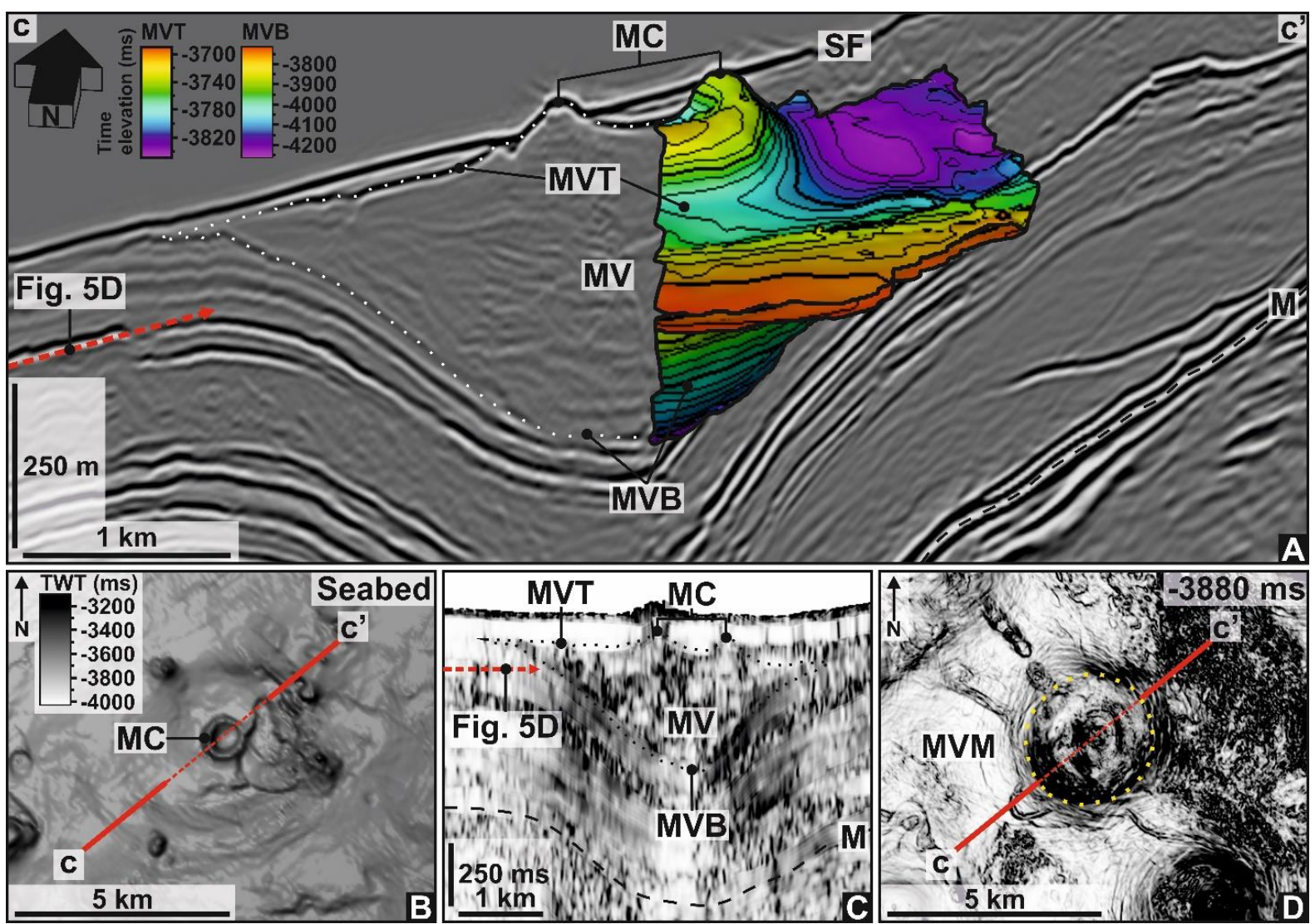

Figure 5. Seismic expression of an extruded mud volcano. (A) 3D visualisation of a mud volcano via a seismic profile through the centre of the extruded edifice (See line C-c' in Fig. 2B for location) and 3D surfaces of its top and base. (B) Seafloor map showing the surface expression and mud cone of the mud volcano in Fig. 5A. (C) Variance profile through the same line of section and mud volcano as in Fig. 5A, that highlights a cone shaped region of discontinuity that characterises the mud volcano. (D) Variance slice through the mud volcano displayed in Fig. 5A and Fig. 5C (See Fig. 5A and Fig. 5C for the position of the time slice) that exhibits a circular area of discontinuity that demarcates the lateral margins of the mud volcano. SF - Seafloor; MC - Mud cone; MV - Mud volcano; MVT - Mud volcano top; MVB - Mud volcano base; MVM - Mud volcano margins; M Horizon M 


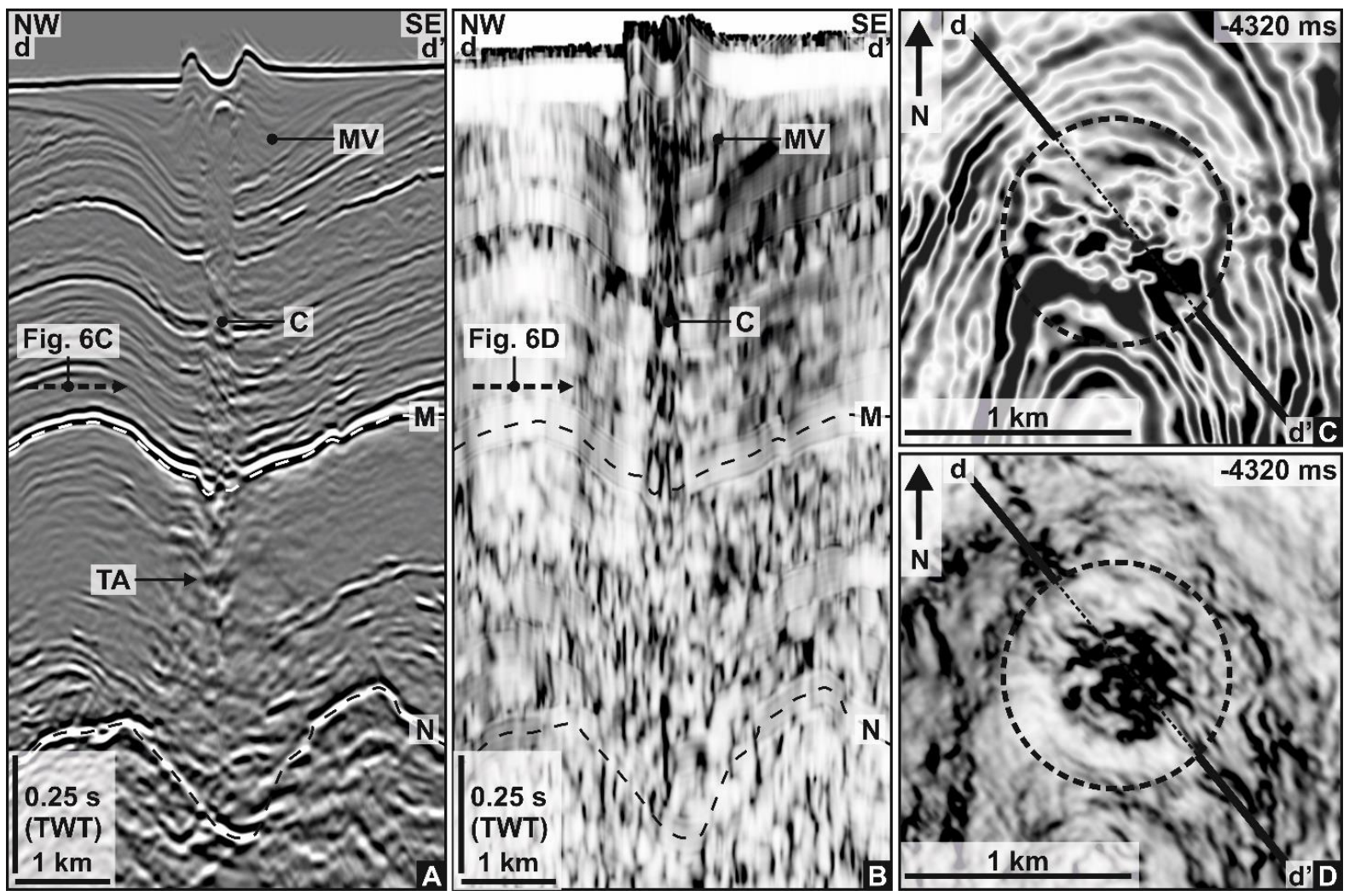

Figure 6. Seismic expression of MVCs. (A) Seismic profile through a mud volcano and its conduit (See line d-d' in Fig. 2B for location). The MVC is characterised as a vertical zone of breaks in reflection continuity and loss of seismic signal. (B) Variance profile of the same line of section in Fig. 6A, that displays the MVC as a vertical zone of discontinuity. (C) Time slice through the MVC (See Fig. 6A for the position of the time slice) that shows a circular to sub-circular are of reduced amplitude and disruption to the reflections of the host succession. (D) Variance slice through the MVC (See Fig. 6B for the position of the slice) that exhibits a circular area of discontinuity that demarcates the lateral margins of the conduit. The dash lined circle in Fig. 6C and Fig. 6D highlights the planform location of the conduit. MV - Mud volcano; C - Conduit; M - Horizon M; N-Horizon N. 


\begin{tabular}{|c|c|c|c|}
\hline & MVC/FEP & Height (m)* & $\begin{array}{c}\text { Average } \\
\text { width (m) }\end{array}$ \\
\hline \multirow{3}{*}{$\begin{array}{c}\text { Mud } \\
\text { volcano } \\
\text { conduits }\end{array}$} & MVC1 & c. 2418 & c. 240 \\
\cline { 2 - 4 } & MVC2 & c. 2499 & c. 300 \\
\cline { 2 - 4 } & MVC3 & c. 2610 & c. 580 \\
\cline { 2 - 4 } & MVC4 & c. 2170 & c. 140 \\
\hline
\end{tabular}

$*=$ Height from Horizon $\mathrm{N}$ to upper terminus.

Table 1 - Dimensions of MVC examples. 


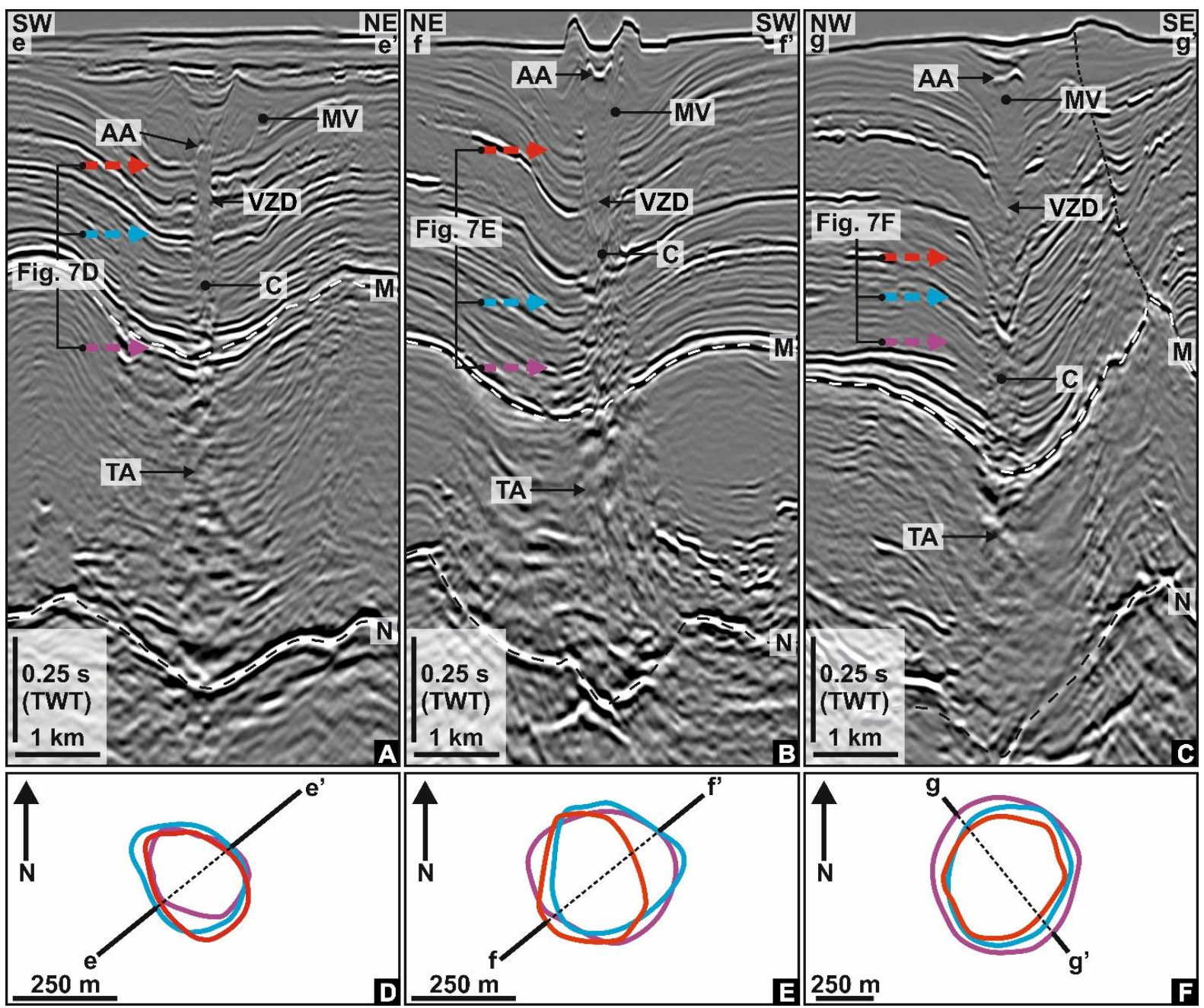

Figure 7. 3D geometry of MVCs. (A) Seismic profile through mud volcano conduit 1 (MVC1) (See line e-e' in Fig. 2B for location). (B) Seismic profile through mud volcano conduit 2 (MVC2) (See line f-f' in Fig. 2B for location). (C) Seismic profile through mud volcano conduit 3 (MVC3) (See line g-g' in Fig. 2B for location). (D) Outlines of the planform margins of MVC1 mapped from variance slices. (E) Outlines of the planform margins of MVC2 mapped from variance slices. (F) Outlines of the planform margins of MVC3 mapped from variance slices. The outlines of the MVC margins are colour coded to relate with the lines of slice displayed in the corresponding seismic profile (See text for detailed description). MV - Mud volcano; C - Conduit; AA Amplitude anomaly; VZD - Vertical zone of discontinuity; TA - Trail of amplification; M - Horizon M; N Horizon N. 

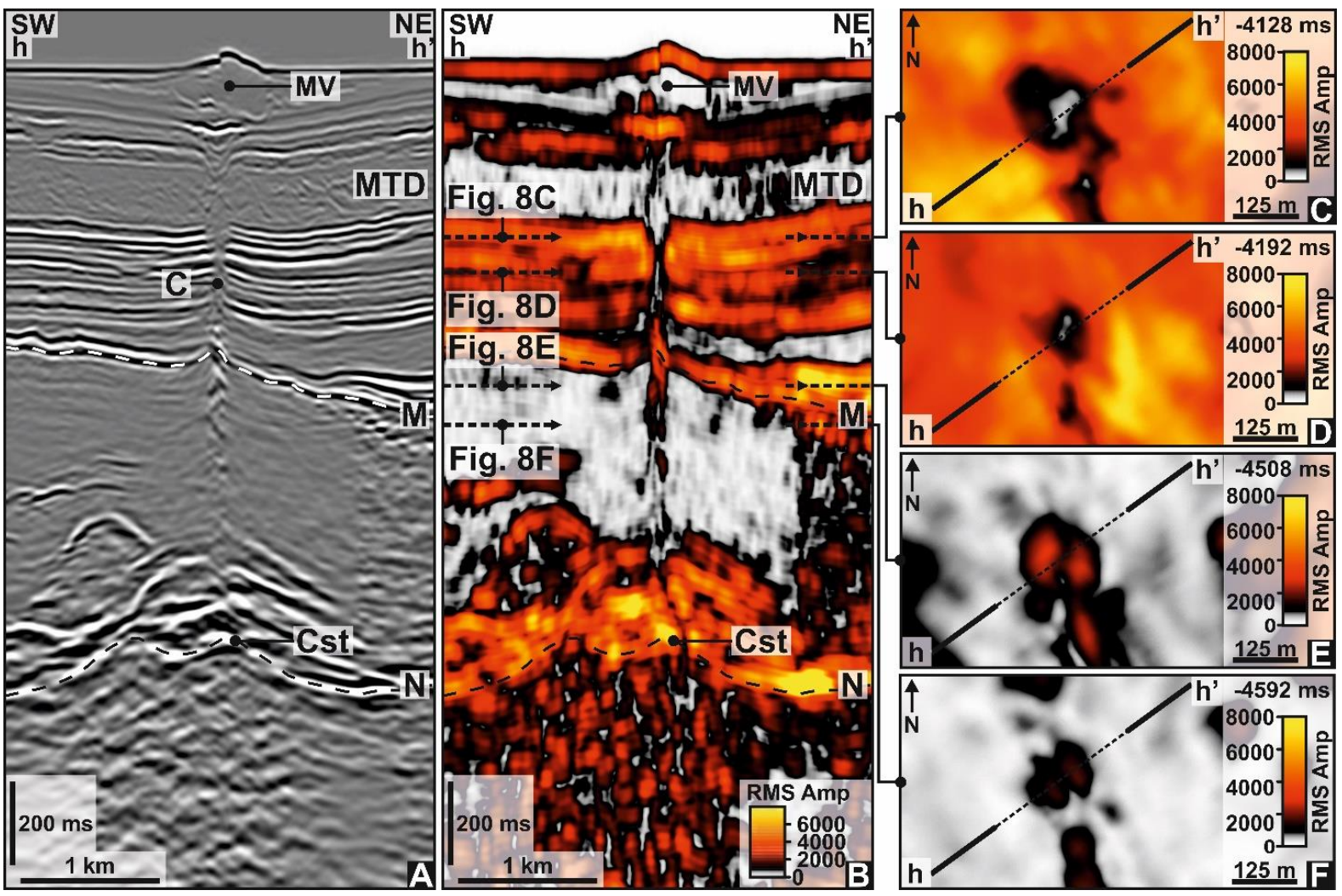

Figure 8. MVC through salt. (A) A seismic profile through a mud volcano and MVC (See line $h-h^{\prime}$ in Fig. 2B for location). The conduit transects the entire Post-Salt Unit, including a mass transport deposit, and is clearly imaged transecting the Messinian Evaporite succession above a base-salt crest. (B) RMS amplitude profile of the same line of section in Fig. 8A that displays the MVC as a vertical zone of low amplitude within the relatively high amplitude Post-Salt Unit. Within the Messinian Evaporite succession, particularly the low amplitude upper section, the MVC is exhibited as a vertical zone of relative high amplitude. (C and D) RMS amplitude slices through the MVC within the Post-Salt Unit (See Fig. 8B for the position of the RMS amplitude slices) showing localised areas of relatively low amplitude compared to the host succession. (E and F) RMS amplitude slices through the MVC within the Messinian Evaporite succession (See Fig. 8B for the position of the RMS amplitude slices) showing localised areas of relatively high amplitude when compared to the low amplitude of the host succession. These localised areas of high amplitude are spatially correlatable with the localised areas low amplitude in Fig. 8C and Fig. 8D. MV - Mud volcano; MTD - Mass transport deposit; C Conduit; Cst - Crest; M - Horizon M; N - Horizon N. 

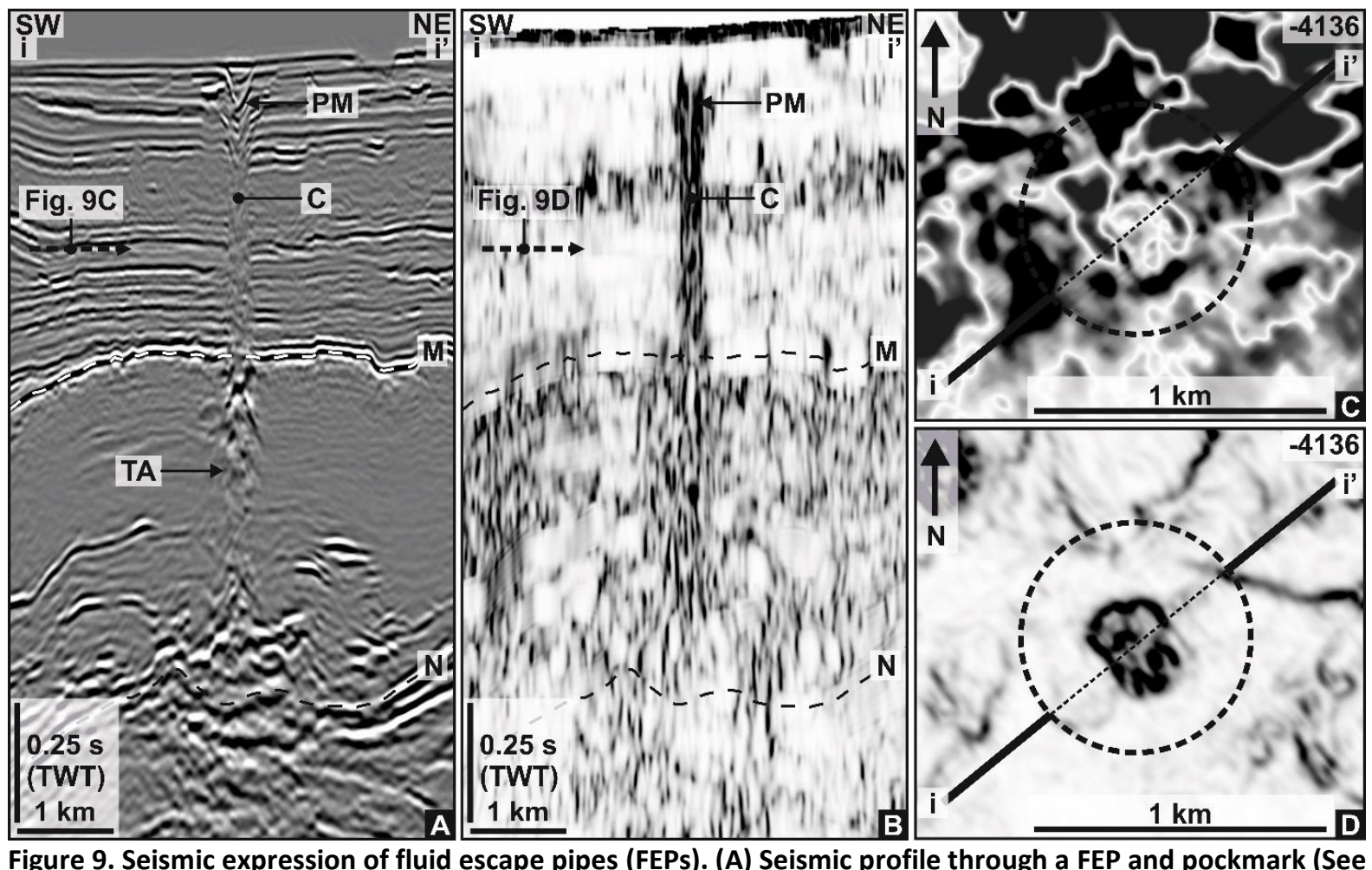

Figure 9. Seismic expression of fluid escape pipes (FEPs). (A) Seismic profile through a FEP and pockmark (See line $\mathrm{i}-\mathrm{i}$ ' in Fig. 2B for location). The FEP is characterised as a vertical zone of breaks in reflection continuity and loss of seismic signal. The pockmark is characterised as a bowl shaped depression at the upper terminus of the pipe. (B) Variance profile of the same line of section in Fig. 9A, that displays the FEP as a vertical zone of discontinuity. (C) Time slice through the FEP (See Fig. 9A for the position of the time slice) that shows a circular to sub-circular area of reduced seismic signal. (D) Variance slice through the FEP (See Fig. 9B for the position of the slice) that exhibits a circular to sub-circular area of discontinuity that displays the lateral margins of the conduit. The dash lined circle in Fig. 9C and Fig. 9D highlight the planform location of the conduit. The seismic expression of the FEP displayed and described here is closely comparable to the MVC presented in Fig. 6. PM - Pockmark; C - Conduit; Trail of amplification; M - Horizon M; N-Horizon N. 
Conduit evolution

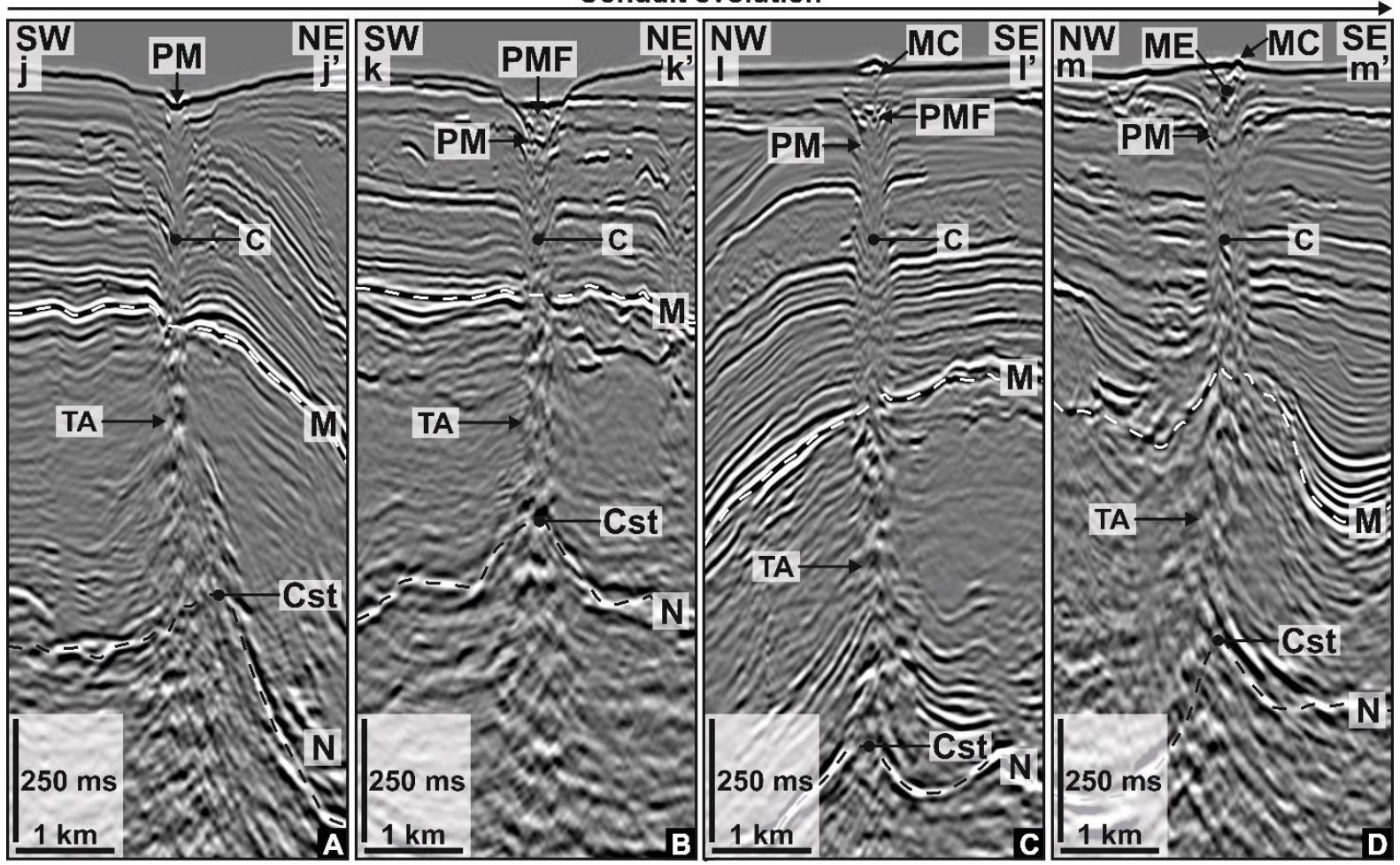

Figure 10. Conduit evolution from FEP to MVC. All of these examples (A-D) exhibit conduits that are located above base-salt crests and transect the entire Messinian Evaporites and Post-Salt Unit, but display different geomorphological features at their upper termini. (A) A FEP with a seafloor pockmark at its upper terminus (See line j-j' in Fig. 2B for location). (B) A FEP with a pockmark at its upper terminus that exhibits a sedimentary fill that is possibly extrusive (See line k-k' in Fig. 2B for location). (C) A pipe-like conduit overlain by a mud cone at the seafloor, potentially the formation of a juvenile mud volcano (See line I-I' in Fig. 2B for location). (D) A MVC feeding a relative small extruded mud edifice (See line m-m' in Fig. 2B for location). PM - Pockmark; PMF - Pockmark fill; MC - Mud cone; ME - Mud edifice; C - Conduit; TA - Trail of amplitude; Cst - Crest; M Horizon; N - Horizon N. 


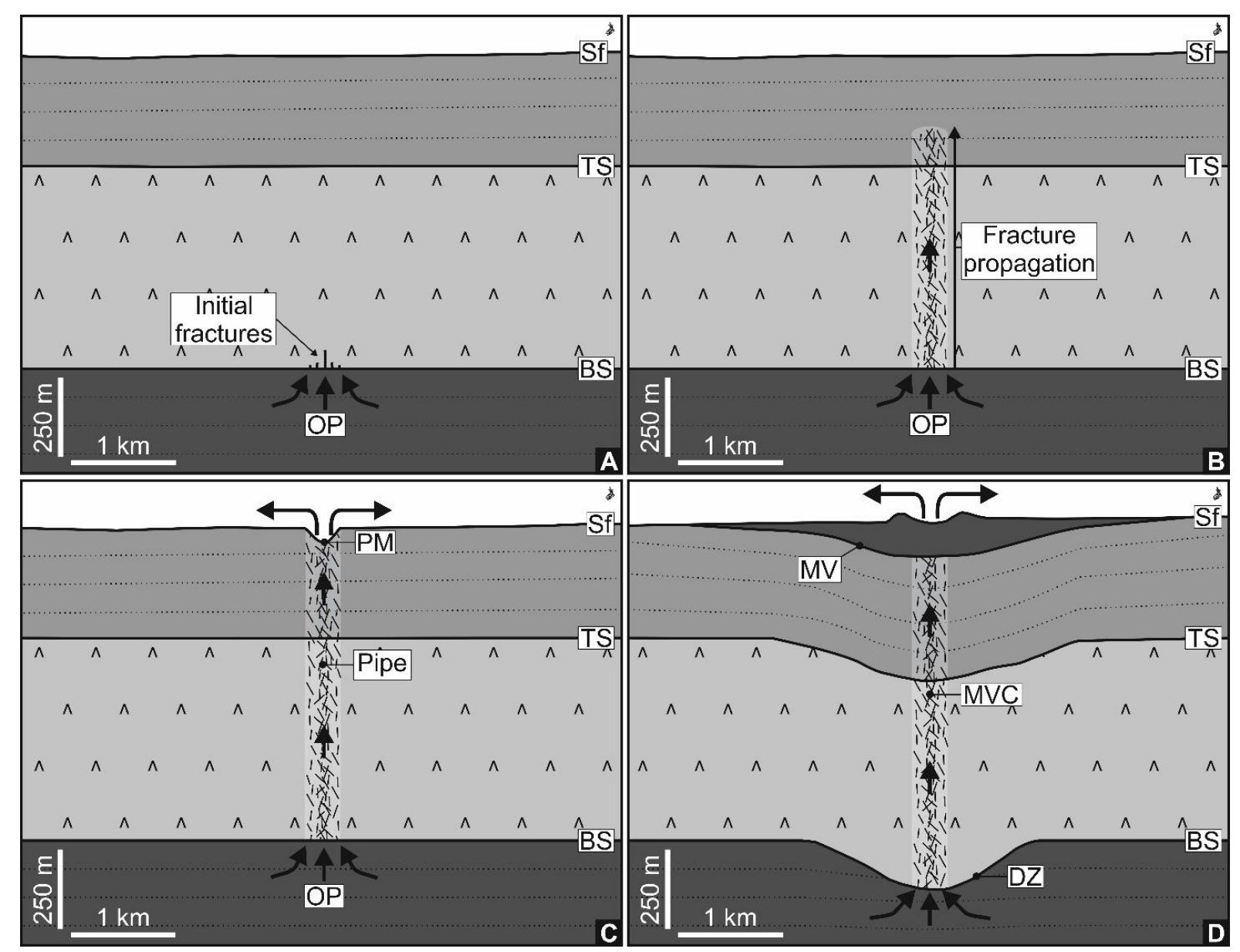

Figure 11. Conceptual model for MVC genesis and propagation through salt. (A) Stage 1 - Overpressure (OP) increases locally above lithostatic beneath the evaporites resulting in the propagation of initial fractures. (B) Stage 2 - Overpressure drives the migration of fluids and liquefied mud into the initially formed fractures within the evaporites, driving the formation of a network of hydraulic fractures that propagate upwards and widen the fractured zone. (C) Stage 3 - Continued upward fracture propagation forms a pipe-like network of hydraulic fractures that pierces the seafloor (Sf) and forms a pockmark (PM), through which fluid rich mud slurry is vented during an early stage of mud volcanism. (D) Stage 4 - Over time mud slurry continues to migrate through the conduit and is extruded over the seafloor, forming a constructional mud volcano. Continued sediment withdrawal from beneath the evaporites forms a depletion zone (DZ), resulting in subsidence of the overburden. Low-salinity fluids migrating through the conduit may result in dissolution of the evaporites and dissociation and collapse of blocks within the conduit via stoping processes, which could contribute to the formation and final character of these MVCs. Arrows represent fluid and sediment migration. TS - Top-Salt; BS - Base-Salt. 